\title{
IRINA EWERS
}

Avaliação imunológica de idosos no pré e pós-operatório de correção de valvulopatia cardíaca

Dissertação apresentada à Faculdade de Medicina da Universidade de São Paulo para obtenção do título de Mestre em Ciências

Área de concentração: Alergia e Imunopatologia Orientador: Prof. Dr. Luiz Vicente Rizzo

SÃO PAULO 2008 


\section{Dados Internacionais de Catalogação na Publicação (CIP)}

Preparada pela Biblioteca da

Faculdade de Medicina da Universidade de São Paulo

Creprodução autorizada pelo autor

\section{Ewers, Irina}

Avaliação imunológica de idosos no pré e pós-operatório de correção de valvulopatia cardíaca / Irina Ewers. -- São Paulo, 2008.

Dissertação(mestrado)--Faculdade de Medicina da Universidade de São Paulo. Departamento de Clínica Médica.

Área de concentração: Alergia e Imunopatologia.

Orientador: Luiz Vicente Rizzo.

Descritores: 1.Idoso 2.Sistema imune 3.Cirurgia torácica 
Esta dissertação é dedicada a Sra. Terezinha Rachel Cattai, minha mãe, O mais importante alicerce da minha vida. 


\section{Agradecimentos}

Ao prof. Dr. Luiz Vicente Rizzo, meu orientador, pela paciência, tolerância, incentivo, orientação, encorajamento e tranqüilidade nos meus momentos de angústia.

Ao prof. Dr. Jorge Kalil pela oportunidade, acolhimento, orientações e acima de tudo, compreensão.

Ao prof. Dr. Max Grimberg por permitir a execução deste trabalho junto ao Ambulatório de Valvopatias do Instituto do Coração do HC-FMUSP.

A todos os assistentes e colegas da Disciplina de Imunologia Clínica e Alergia do HC-FMUSP, pelas sugestões e críticas durante o desenvolvimento deste projeto.

Ao Serafim, Rosana e Leoni, do Ambulatório de Imunologia Clínica e Alergia HC-FMUSP, grandes amigos, enorme colaboração.

Aos amigos Sumaia, Lúcia, Angely, Silvia Simões, Rosana Agonde, Gabriela Lentulo, Ana Cristina Serrano Catta-Preta, Sr. Osvaldo e Sra. Olga pelo companheirismo e incentivo desde o início deste projeto.

À banca de qualificação desta dissertação Dra. Cristina Maria Kokron, doutora na área de Pediatria da UNIFESP e médica assistente da Disciplina de Imunologia Clínica e Alergia do HC-FMUSP; Prof. Dr. Heraldo Possolo de Souza pela disciplina de Emergências Clínicas da FMUSP e doutor em medicina pela FMUSP e Dr Roney Orismar Sampaio, doutor em medicina pela FMUSP e médico assistente da Unidade Clínica de Valvopatias do Instituto do Coração do HC-FMUSP, pelas críticas, sugestões e principalmente pela credibilidade e confiança. 
À Tânia, nossa secretária, pelo grande apoio e amizade e sem os quais, este trabalho não estaria concluído.

Ao Dr. Carlos Roberto de Medeiros pela ajuda incondicional, com sugestões e execução da análise estatística.

A Deus por permitir a chegada do meu companheiro Clayton Ucci de Carvalho no momento em que eu mais precisava de equilíbrio emocional.

E ao Dr. Jean Pierre Schatzmann Peron meu tutor, laboratório de Imunologia Clínica, ICB IV-USP pela doação do seu tempo e de seus conhecimentos na finalização deste projeto. 


\section{Sumário}

Lista de abreviaturas

RESUMO

SUMMARY

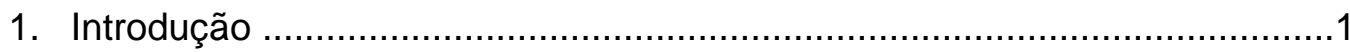

1.10 Envelhecimento dos Seres Humanos....................................................1

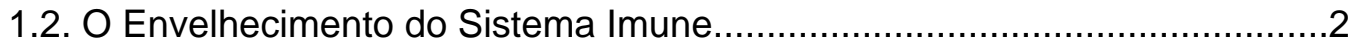

1.3. Cirurgia de Valva Cardíaca $x$ Sistema Imune...........................................

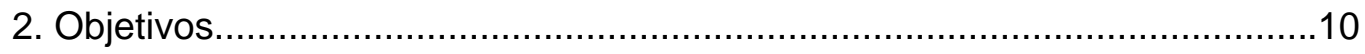

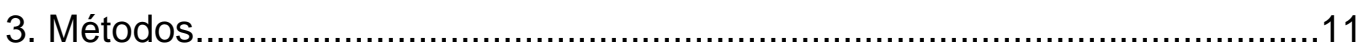

3.1. Delineamento do estudo e da população.................................................11

3.2. Determinação do perfil psicológico.......................................................12

3.3. Determinação do Índice de Massa Corpórea............................................12

3.4. Determinação da realização de atividade física........................................13

3.5. Coleta das amostras sangüíneas........................................................13

3.6. Ensaios de proliferação com mitógenos e antígenos................................13

3.7. Marcação de células e análise por citometria de fluxo ( FACS).................15

3.8. Determinação da produção de citocinas por ELISA..................................15

3.9. Testes cutâneos de hipersensibilidade tardia...........................................17

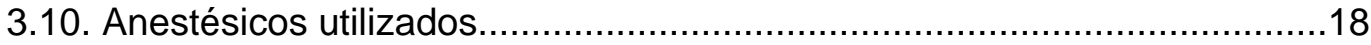

3.11. Locais de execução dos experimentos................................................18 


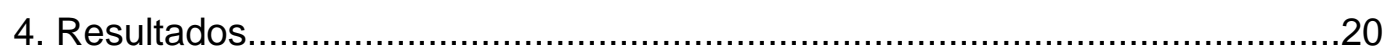

4.1. Distribuição das variáveis epidemiológicas ...........................................20

4.2. Teste cutâneo de hipersensibilidade tardia.............................................21

4.2.1 Teste cutâneo de hipersensibilidade tardia com candidina, PPD e

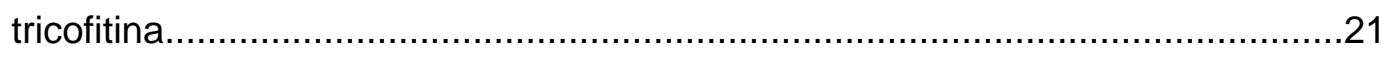

4.3. Ensaios de proliferação para mitógenos e antígenos.............................23

4.3.1. Linfoproliferação frente ao estímulo com Con A, PHA, PPD e TT..........23

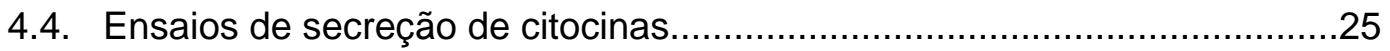

4.4.1.Quantificação de IL-2 em sobrenadante de cultura de PBMCs................25

4.4.2. Quantificação de IL-4 em sobrenadante de cultura de PBMCs..............27

4.4.3. Quantificação de IFN- $\gamma$ em sobrenadante de cultura de PBMCs..........29

4.4.4. Quantificação de IL-12 em sobrenadante de cultura de PBMCs............ 31

4.4.5.Quantificação de IL-8 em sobrenadante de cultura de PBMCs..................33

4.5.Análise da porcentagem de populações celulares e da expressão marcadores de superfície celular através da citometria de fluxo......................35

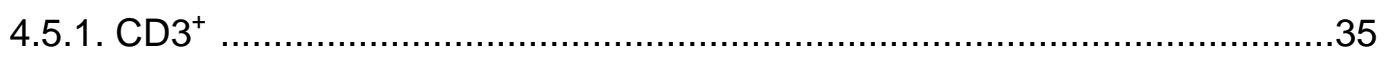

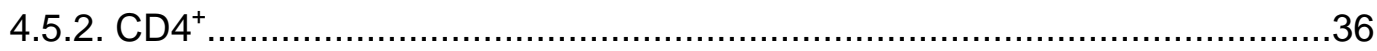

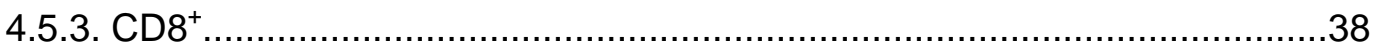

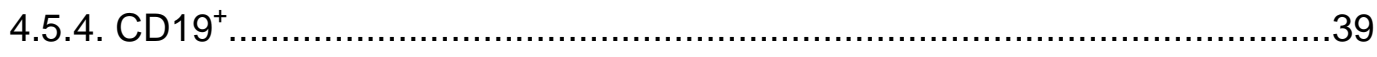

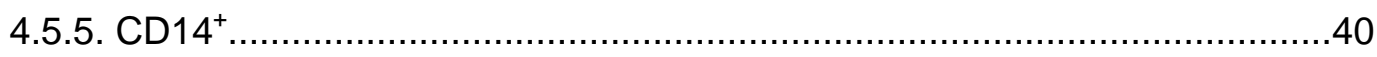

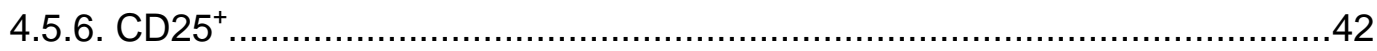

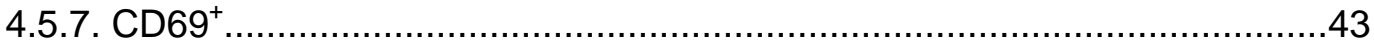

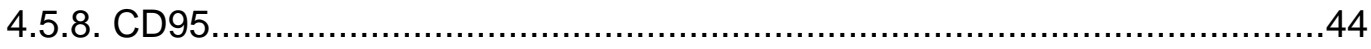




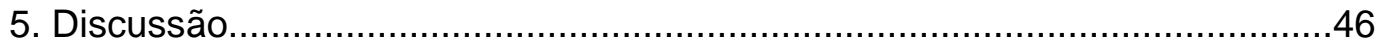

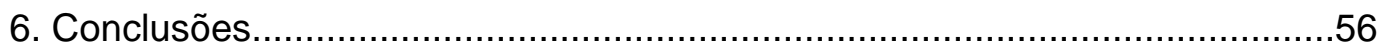

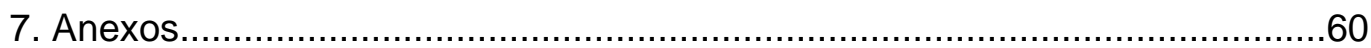

7.1. Anexo A: Termo de consentimento esclarecido......................................60

7.2. Anexo B: Comissão de Ética CAPPesq..................................................62

7.3. Anexo C: Inventário Becker de depressão (Questionário definidor

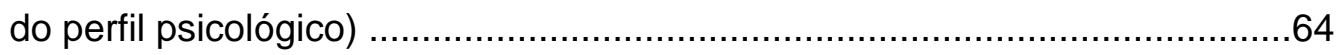

7.4. Anexo D: Avaliação da realização de atividade física.............................71

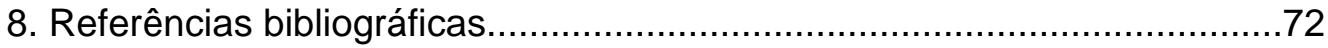


Ewers I. Avaliação imunológica de idosos no pré e pós-operatório de correção de valvulopatia cardíaca [dissertação]. São Paulo: Faculdade de Medicina, Universidade de São Paulo; 2008

Sabe-se que o sistema imune, através de um fenômeno denominado imunossenescência, gradativamente diminui a sua capacidade de resposta durante a vida. Este fato pode tornar o indivíduo mais suscetível a infecções e outras patologias. Neste contexto, seria útil procurar por fatores que alterassem esta evolução natural, principalmente os capazes de acelerar este processo. Por esta razão, nós procuramos por diferenças nos parâmetros imunológicos entre o antes e o depois da cirurgia de valva cardíaca em idosos com mais de 65 anos. Nossos resultados não apontaram, no pós-operatório, para uma diminuição da capacidade imune, uma vez que os testes cutâneos de hipersensibilidade para o PPD, tricofitina e candidina não se alteraram. Quando a resposta linfoproliferativa foi avaliada in vitro, também não apresentou diferença. Por outro lado, nós observamos um aumento na porcentagem de células $\mathrm{T} \mathrm{CD}^{+}, \mathrm{T} \mathrm{CD}^{+}$e monócitos no sangue periférico, quando comparamos os períodos. Sendo que os marcadores de ativação cellular CD25 ${ }^{+}$ ,CD69 ${ }^{+}$e o CD95 também se apresentaram elevados. Quanto a secreção de 
citocinas, nossos resultados apontam para um amento de IL-4 e IL-8. Inversamente, concentrações reduzidas de IL-2, IL-12 e IFN- $\gamma$ foram detectadas no sobrenadante de PBMCs quando estimuladas in vitro. Em suma, nossos dados demonstram que a cirurgia de valva cardiaca é capaz de alterar vários parâmetros da resposta immune, com um aumenrto da porcentagem de células, quanto da expressão de marcadores de ativação celular e secreção de citocinas.

Descritores: 1-Idosos 2- Sistema Imune 3- Cirurgia torácica 
Ewers,I. Immune evalution of elderly subjects submitted to valvulopathy correction surgery. [dissertation]. São Paulo: Faculdade de Medicina, Universidade de São Paulo; 2008.

It is known that the immune system, through a phenomenon called immunosenescence, undergoes functional changes during life which may culminate in a diminished capacity of response, turning the subject more susceptible to infections and other pathologies. In this context, it is useful to search for factors that alter this natural evolution, mainly able to delay this process. For this reason, we assessed different immunologic parameters before and after cardiac valve surgery in 65 year-old patients. Our results did not point to a postoperative immunedeficiency-like state, once that the cutaneous tests to PPD, candidin and tricophytin remained positive for most of the subjects. When the proliferative response was assessed in vitro, there were also no differences. On the other hand, we observed a post-surgical increase in the percentage of $T$ $\mathrm{CD}^{+}, \mathrm{T} \mathrm{CD}^{+}$cells and in monocytes from peripheral blood when we compare both periods. Moreover, it is important to highlight that activation markers, such as CD25, CD69 and CD95 were also presented in higher levels. According to the cytokine secretion, our results appointed to a greater secretion of IL-4 and IL-8 postoperative. Conversely, reduced concentrations of IL-2, IL-12 and IFN- $\gamma$ were detected in supernatant of PBMCs when stimulated in vitro. In summary, our data reveal that the cardiac valve surgery with extra corporeal procedure and anesthesia is able to alter several parameters of the immune response, with an increased percentage of the major assessed cells, as well as in the expression of activation markers and cytokine secretion.

Descriptors: 1- Ageing 2- Immune System 3- Thoracic Surgery 
Lista de abreviaturas, siglas e símbolos

CAPPesq Comissão de Ética para Análise de Projetos de Pesquisa

CEC circulação extra-corpórea

Con A

Concanavalina A

DC

células dendríticas

DP

desvio padrão

FMUSP

Faculdade de Medicina da Universidade de São Paulo

FITC

isotiocianato de fluoresceína

$\mathrm{HC}$

Hospital das Clínicas

IBGE

Instituto Brasileiro de Geografia e Estatística

ICB-USP

Instituto de Ciências Biomédicas da Universidade de SP

InCOR

Instituto do Coração

IMC

índice de massa corpórea

IL-1

citocina 1

IL-2

citocina 2

IL-4

citocina 4

IL-8

citocina 8

IL-12

citocina 12

IFN- $\gamma$

Interferon-gama

JNK

c-jun $\mathrm{N}$-terminal quinase

$\mathrm{Kg}$

quilograma

LPS

lipopolissacáride 
metro

$\mathrm{m}^{2}$

metro quadrado

mAb

anticorpo monoclonal

$\mathrm{ml}$

mililitros

$\mathrm{Mm}$

milímetro

NK

natural killer

OMS

Organização Mundial de Saúde

PBMCs

células mononucleares de sangue periférico

PE

ficoeritrina

PHA

fitohemaglutinina

PPD

Micobacterium tuberculosis

TCR

receptor do linfócito T

Th1

linfócito T auxiliador do tipo1

Th2

linfócito T auxiliador do tipo 2

TT

toxóide tetânico

$\mu l$

microlitros 


\section{INTRODUÇÃO}

\subsection{O Envelhecimento dos Seres Humanos}

A prevalência de indivíduos idosos, em detrimento aos indivíduos jovens, compreende um quadro comum na população mundial (Novaes et al., 2005). A Organização Mundial de Saúde (OMS) considera idoso o indivíduo com idade superior a 65 anos. Em 2007, o Brasil possuía mais de 20 milhões de idosos, conforme dados do Instituto Brasileiro de Geografia e Estatística (IBGE - 2007).

Terceira idade (termo criado na França, na década de 60, pelo gerontologista Huet, e amplamente utilizado em nosso país) surge para expressar novos padrões comportamentais de uma geração que se aposenta e envelhece ativamente (Silva, 2008). O crescimento desta população é explicado, por especialistas em estudos demográficos, pela queda da taxa da fecundidade aliada à queda da taxa de mortalidade, como conseqüência do avanço da medicina que, além de combater as epidemias que ceifavam vidas jovens, controla melhor doenças crônicas e degenerativas.

A expectativa de vida no Brasil em 1940, foi de 40,5 anos; em 2007, foi de 72,3 anos; e em 2050, poderá ser de 81,3 anos (IBGE - 2007). A conseqüência em se viver mais, além do aumento da susceptibilidade para infecções, doenças auto-imunes e câncer (Gupta et al., 2005; Aw et al., 2007), é o aparecimento de doenças cardiovasculares inerentes aos idosos, 
dentre as quais, destacamos as doenças degenerativas das valvas cardíacas (Abdalla et al., 1992). As alterações nas valvas cardíacas podem, em um determinado momento, necessitar de correção cirúrgica. Indica-se a cirurgia para alívio dos sinais e/ou sintomas, tais como: angina, síncope e insuficiência cardíaca. Com isto, pretende-se a melhora da capacidade física e, conseqüentemente, preservar a qualidade de vida destes indivíduos.

\subsection{O Envelhecimento do Sistema Imune}

Durante toda a vida do ser humano, seu sistema imune sofre continuamente mudanças morfológicas e funcionais, atingindo o pico da sua função imune na puberdade e apresentando um declínio gradual com o envelhecimento( Ramos-Casals et al., 2003; Goronzy et al, 2006). Imunossenescência é o termo utilizado para definir mudanças no sistema imune causadas pelo envelhecimento, e que acarreta na diminuição da eficiência das respostas imunes (Aw et al., 2007; Simone et al.,2008) . Este declínio da função imune, encontrado nos humanos e também comprovado em camundongos idosos (Jiang et al., 2007), está associado a alterações que ocorrerem em qualquer etapa do desencadeamento da resposta imune. Estas mudanças parecem ocorrer, de um modo geral, em indivíduos após os 60 anos de idade (Franceschi et al.,1996; Pawelec, 2006; Aw et al., 2007). Durante o processo de envelhecimento, o timo sofre uma série de alterações que afetarão diretamente a produção de células $T$, o que determina um declínio na imunidade celular mediada (Dennett et al., 2002; Tarazona et al., 
2002). Sua principal alteração anátomo-histológica (Malaguarnera et al., 2001) é a involução (Globerson et al., 2000; Sansoni et al., 2008), mas o envelhecimento inclui também mudanças no número e na função de outras células do sistema imune inato ( Solana et al., 2000). As células T são as que maior vulnerabilidade teriam aos potenciais efeitos deletérios do envelhecimento. $O$ declínio da atividade da célula $T$ foi primeiramente descrito em camundongos por Menon et al., e em humanos, por Weksler et al., ambos em 1974. Através do desencadeamento de eventos seqüenciais, ocorre uma sinalização perfeita da célula $T$. Esta sinalização se manifesta por ativação, diferenciação, apoptose, anergia, desenvolvimento de funções efetoras ou de memória (Miller et al., 1997). Todas essas manifestações são moduladas por uma relativa proporção de sub-populações de células $T$, receptores co-estimulatórios, composição da membrana celular, tipo de célula apresentadora de antígeno ou equilíbrio entre as citocinas produzidas. Quando há uma ruptura nesta cascata de sinalização, causada por mudanças fisiológicas, pelo envelhecimento ou patológicas como o câncer ou doenças auto-imunes, a resposta imune se altera. Idosos estão mais sujeitos a estas mudanças e, ao se somarem com alterações inerentes à idade, resulta num comprometimento importante das funções do sistema imune. Defeitos na ativação celular também têm sido descritos como conseqüência do envelhecimento do sistema imune. A enzima c-jun $\mathrm{N}$ terminal quinase (JNK), que é ativada quando linfócitos T são estimulados via receptor para antígeno (TCR) e pela molécula CD28 ( contribuindo para a produção de interleucina-2 através da fosforilação dos seus fatores de 
transcrição), tem sua atividade diminuída, em até duas vezes, nos camundongos idosos (Miller., 1997; Kirk et al., 1999).

Sabe-se que há uma grande interação entre sistema imune e sistema nervoso, e o papel que esta ligação tem na exacerbação de afecções de cunho imunológico, bem como na depressão das funções normais do sistema imune (McEwen, 2007). Aparentemente, indivíduos idosos estão ainda mais sujeitos a estes efeitos (Grahan et al., 2006). envelhecimento resulta na redução da competência adaptativa ao estresse através da diminuição da resposta simpática, causada: 1- pela diminuição do número de receptores de catecolaminas nos tecidos-alvo periféricos; 2- pelo declínio das proteínas de choque térmico ( as quais aumentam a resistência ao estresse); e pela diminuição da competência das catecolaminas em induzir a produção dessas proteínas (Udelsman et al.,1993). A imunossenescência está associada a mudanças nos níveis de glicocorticóides, e linfócitos periféricos de idosos respondem pobremente, in vitro, ao estímulo com glicocorticóides (Frauwirth et al., 2002; Bauer, 2005). A teoria da senescência celular pode ser explicada de duas formas: uma induzida pelo estresse, que ocorre em resposta aos eventos moleculares, e a outra mediada pela exaustão replicativa. Esta exaustão é também chamada hipótese de Hayflick e se sustenta pelo conhecimento de que o telômero age como um relógio mitótico, na medida em que ele encurta a cada ciclo de replicação celular. Quando o limite crítico do encurtamento do telômero é atingido, a célula entra em estado de senescência e sua capacidade de reparar danos ao DNA fica prejudicada. Há um consenso de 
que essa alteração seja muito mais qualitativa do que quantitativa (Goronzy et al., 2006).

Os principais mediadores da resposta imune são as citocinas- moléculas solúveis que controlam diferentes funções das células incluindo proliferação, diferenciação, morte celular (apoptose ou necrose), sobrevivência e migração- sejam diretamente, através de eventos que se seguem à ligação de seus receptores específicos na superfície celular, ou indiretamente, através da indução da expressão de numerosos genes (Fülöp et al., 2006). Uma perda no equilíbrio entre as citocinas do padrão Th1 e Th2 em idosos também foi descrita (Bonagura et al.,1999), e isto pode ser responsável, pelo menos em parte, pelo aumento da suscetibilidade destes indivíduos a infecções virais e de bactérias extracelulares.

As células apresentadoras de antígeno mais importantes são as células dendríticas (DC), que tem o papel fundamental em fazer a ponte entre a resposta imune inata e a adquirida (Banchereau et al.,1998; Cella et al. ,1997; Inaba et al.,1990; Banchereau et al., 2000). Estas células podem tanto induzir uma potente resposta antígeno-específica, como mediarem tolerância (Steinman et al., 2003). Estão localizadas em diversos pontos pelo organismo, notadamente naqueles em que a evolução determinou serem os de maior exposição a microorganismos invasores. São responsáveis por iniciar e amplificar a resposta imune, através de uma rede que inclui outras células apresentadoras de antígenos, fagócitos e células do endotélio vascular. Nas situações em que não precisam estar atuando, mantêm-se imaturas e induzem tolerância periférica aos auto-antígenos através, dentre 
outras coisas, da amostragem de antígenos oriundos de células próprias em apoptose. Existem diferentes populações de DC, e suas interações com os diversos tipos de linfócitos $\mathrm{T}$ ajudam a determinar o caminho ao qual uma resposta imune irá trilhar (sendo, muitas vezes, o fator mais importante).

Outra célula bastante estudada é a natural killer (NK), a qual, além da atividade citotóxica, regula a resposta imune pela produção de citocinas e quimocinas que participam diretamente na eliminação de patógenos ou na atividade de outras células componentes da imunidade. Há controvérsias quanto ao número de células NK no sangue de indivíduos idosos, visto que, enquanto certos estudos apontam para diminuição, outros indicam a manutenção (Lighthart et al., 1989; Ligthart et al., 1990) e, até mesmo, um aumento no número e atividade ( Sansoni et al.,1993). Alguns autores sugerem, então, que valores persistentemente baixos no número e atividade citotóxica de células NK, em idosos, não são uma constante, e sim, marcadores de morbidade e mortalidade neste grupo de indivíduos (Franceschi et al., 1996). A atividade NK está correlacionada com níveis séricos de vitamina $D$ e, portanto, a qualidade da nutrição é fator importante nos idosos, bem como a realização de atividades físicas (Borrego et al., 1999). Sendo assim, o estado nutricional tem um papel crucial na manutenção da função imune, independentemente da idade do indivíduo. A qualidade da nutrição e a realização de atividade física em muito pode contribuir para a preservação da atividade do sistema imune (Han et al., 1999; Shor-Posner et al., 1999). O declínio nos parâmetros específicos e inespecíficos da imunidade tem sido associado à desnutrição e à deficiência 
de proteínas, apresentando-se como um fator contribuinte para o aumento da mortalidade em idosos, especialmente quando relacionado ao câncer e às doenças infecciosas (Krause et al., 1999). Os idosos que mantêm atividade física contínua apresentam níveis de linfócitos T CD4+ e CD8+ semelhantes aos dos jovens sedentários e não apresentam defeitos comuns de recrutamento de linfócitos para os sítios infecciosos, os quais são observados em idosos sedentários (Bruunsgaard et al., 1999).

A maioria das análises mostra pouca ou nenhuma modificação do número de linfócitos B no sangue periférico de idosos. Ocorrem poucas modificações nos níveis de anticorpos, incluindo $\lg A$, $\lg M$ e $\lg G$, e alguns outros estudos indicam um aumento de IgA, IgG e talvez IgE (Franceschi et al., 1996).

A morte celular por apoptose desempenha um papel importante na embriogênese, homeostase celular, atrofia tecidual e remoção de células tumorais ou danificadas. No sistema imune, tem um papel crucial na seleção do repertório de linfócitos $T$ no timo, deleção de linfócitos $T$ e $B$ autoreativos, regulação da memória imunológica e das células NK (Gupta et al.,2005). Durante o envelhecimento, existe uma linfopenia progressiva de células $\mathrm{T}$, tanto $\mathrm{CD} 4+$ como $\mathrm{CD} 8+$, causada pelo decréscimo de precursores na medula óssea, redução do potencial proliferativo e/ou aumento da apoptose. Este aumento da apoptose pode estar relacionada com um aumento na expressão de CD95. Não está claro, porém, se existe algum tipo de impacto do aumento da apoptose de células T no repertório específico de linfócitos (De Martins et al., 2007). 


\subsection{Cirurgia de Valva Cardíaca X Sistema imune}

Uma cirurgia de valva cardíaca pode ter duração de 2 a 3 horas, sob anestesia geral, com utilização de circulação extra-corpórea (CEC). A CEC é responsável pela realização das funções cardíaca e pulmonares durante o ato cirúrgico. Os pacientes recebem transfusão de sangue no intra e/ou pósoperatórios. Alguns estudos sugerem que a cirurgia cardíaca pode causar mudanças na imunidade celular mediada (Hisatomi et al.,1989; Markewitz et al., 1993), enquanto outros investigaram mudanças no padrão de citocinas (Faist et al.,1991; Jansen et al.,1991; Abacilar et al., 2006).Os efeitos adversos na resposta imune, ocasionados por anestésicos, têm um papel no desencadeamento de infecções pós-operatórias (Naldini et al.,1999). Outro importante aspecto a se considerar é o possível efeito imunossupressor da CEC, o qual induz a produção de mediadores antiinflamatórios que podem contribuir para a morbimortalidade no período do pós-operatório (Valen et al., 2001). A CEC impõe ao organismo um número de alterações importantes: desvia o sangue para um circuito artificial; muda o regime do fluxo sangüíneo; possivelmente, aumenta o gradiente de temperatura; e causa um estresse mecânico sobre os elementos figurados do sangue, devido ao seu contato com superfícies não endoteliais, filtros, compressão e turbulências (Pertilä et al.,1994).

Diante de todos estes dados, qual o impacto de uma cirurgia de correção ou troca de qualquer uma das valvas cardíacas em um sistema imune já alterado pelo envelhecimento? Nosso estudo está baseado na 
análise do perfil de secreção de citocinas; na avaliação da porcentagem de populações celulares no sangue periférico; na expressão de marcadores de superfície; na determinação da capacidade proliferativa celular frente a estímulos mitogênicos e antigênicos; na interpretação de testes cutâneos de hipersensibilidade tardia; no grau de atividade física realizada; no estado nutricional; no perfil psicológico; e em alguns dos parâmetros associados ao ato cirúrgico, como o tempo ao qual o indivíduo ficou submetido à CEC, os anestésicos utilizados e o tempo de estocagem das bolsas de sangue transfundidas. A partir disto, poderemos esclarecer possíveis alterações da resposta imune no pós-operatório da nossa população de idosos valvopatas. 


\section{OBJETIVOS}

O objetivo deste estudo foi avaliar o impacto da cirurgia de correção de valvulopatia, na atividade do sistema imunológico, comparando-se os períodos pré e pós-operatórios, em pacientes com mais de 65 anos, utilizando os seguintes parâmetros:

1) Secreção de citocinas: IL-2, IL-4, IL-8, IL-12 e IFN- $\gamma$;

2) Avaliação da porcentagem de populações celulares: CD3+, CD4+, CD8+, CD14 ${ }^{+}$e CD19

3) Expressão de marcadores de ativação celular: $C D 25^{+}, \mathrm{CD} 69^{+}$e CD95

4) Determinação da capacidade proliferativa celular frente a estímulos mitogênicos PHA e Con A e antigênicos PPD e TT;

5) Testes cutâneos de hipersensibilidade tardia frente à candidina, PPD e tricofitina 


\section{MÉTODOS}

\subsection{Delineamento do estudo e da população}

Um estudo observacional de coorte prospectivo foi realizado a partir de uma amostra de 50 pacientes com 65 anos ou mais, selecionados do ambulatório de valvopatias do Instituto do Coração (InCOR) do Hospital das Clínicas da Faculdade de Medicina da Universidade de São Paulo (HCFMUSP), no período de janeiro de 2002 a dezembro de 2006, e que tinham programação de correção cirúrgica pela valvopatia cardíaca.

Numa primeira abordagem, explicamos a pesquisa e solicitamos, em caso positivo de participação, leitura e assinatura do termo de consentimento livre e esclarecido (Anexo A).

Indivíduos portadores de Diabetes Mellitus, doença auto-imune em atividade, neoplasia, infecção crônica ou uso de medicamentos com atividade imunossupressora, foram excluídos do estudo.

O projeto obteve aprovação da Comissão de Ética para Análise de Projetos de Pesquisa (CAPPesq) da Diretoria Clínica do Hospital das Clínicas da Faculdade de Medicina da Universidade de São Paulo, sob o número 015/06 (Anexo B). Todos os pacientes leram e assinaram o termo de consentimento livre e esclarecido antes da inclusão no estudo. 


\subsection{Determinação do perfil psicológico}

O Inventário Beck de Depressão (BDI - Beck Depression Inventory) (Anexo C), pelo fundamento teórico que o embasa, valoriza muito mais a categoria dos sintomas cognitivos os quais incluem desesperança, desamparo, idéias de culpa (que podem chegar a delírios de culpa em depressões psicóticas) e de suicídio, indecisão, perda de insight, isto é, do reconhecimento de que está doente. Este inventário é a medida de autoavaliação de depressão mais amplamente utilizada tanto em pesquisa como em clínica. Para determinarmos a existência de um quadro depressivo maior, fator este que interfere na função do sistema imune (Guidi et al,1998), todos os participantes do estudo foram submetidos a este questionário.

\subsection{Determinação do Índice de Massa Corpórea}

Pelo Índice de Massa Corpórea (IMC), cuja fórmula calcula-se pelo peso em $\mathrm{kg}$ dividido pela altura ${ }^{2}$, podemos classificar os pacientes quanto ao seu equilíbrio nutricional:

$<18,5 \mathrm{~kg} / \mathrm{m}^{2}$ baixo peso,

entre $18,6 \mathrm{~kg} / \mathrm{m}^{2}$ e $24,9 \mathrm{~kg} / \mathrm{m}^{2}$ normal e

$>25 \mathrm{~kg} / \mathrm{m}^{2}$ sobrepeso

$>30 \mathrm{~kg} / \mathrm{m}^{2}$ obesidade 


\subsection{Determinação da realização de atividade física}

Através de um questionário com perguntas objetivas, determinamos o quanto de atividade física cada idoso realizava ( Anexo D).

\subsection{Coleta das amostras sangüíneas}

Foram coletados $70 \mathrm{ml}$ de sangue venoso, entre 5 a 7 dias antes e depois do procedimento cirúrgico através de punção venosa com tubos contendo EDTA como anti-coagulante. As amostras foram processadas imediatamente após a coleta.

\subsection{Ensaios de proliferação com mitógenos e antígenos}

Os ensaios de proliferação de células T, na presença de antígenos e mitógenos, foram executados em meio de Eagle modificado por Dulbecco (DMEM), acompanhadas de respectivos poços controles sem estimulação antigênica e mantida em estufa à $37^{\circ} \mathrm{C}$, com atmosfera de $10 \%$ de $\mathrm{CO} 2$, durante 48 horas. O meio de cultura foi suplementado com aminoácidos não essenciais $0.1 \mathrm{mM}$, vitaminas $0.1 \mathrm{mM}$, piruvato de sódio $1 \mathrm{mM}$, L-glutamina $2.0 \mathrm{mM}$, e 3-mercaptoetanol $10^{-5} \mathrm{M}$, obtidos da Life Sicence Technologies (Grand Island, NY, EUA). Timidina triciada ( 3 $\mathrm{H}-\mathrm{TdR}$, methyl-3 $\mathrm{H}$ thymidine $0,5 \mu \mathrm{Ci} /$ poço, Amershan International, USA) foi acrescida 16 horas antes da finalização do tempo de cultura. Ao 
término do tempo, as culturas celulares foram coletadas em filtros através do "cell harvester"( Cambridge technology Inc., Watertow, MA, USA), e a radioatividade foi mensurada através de cintilação (1 litro de tolueno; $4 \mathrm{~g}$ PPO; 0,1g POPOP) em aparelho contador de radiação beta ( Beckman $L$ S 100C). As células utilizadas para o teste de proliferação foram de sangue venoso, obtidas através de centrifugação em gradiente de densidade (Isolymph, Rehovot, Isrrael). Após três lavagens em meio de cultura contendo $0.5 \%$ de soro humano $A B+$ de doadores masculinos (Gemini Bio- Products, CA, EUA), as células foram adicionadas em triplicatas a placas de 96 poços para cultura obtidas da Linbro (ICN/Flow, Costa Mesa, CA, EUA), num volume final de $200 \mu$ le meio contendo $5 \%$ soro humano $A B+$ da mesma procedência descrita acima. A proliferação para os antígenos foi medida usando concentrações pré-determinadas das proteínas em questão (PPD $100 \mu \mathrm{g} / \mathrm{ml}$ e TT $30 \mu \mathrm{g} / \mathrm{ml}$ ) e para os mitógenos (PHA $50 \mu \mathrm{g} / \mathrm{ml}$ e ConA 2,5 $\mu \mathrm{g} / \mathrm{ml}$ ). A proliferação basal foi medida em poços contendo apenas as células testadas em meio de cultura. A resposta proliferativa foi avaliada 96 horas após o estímulo com antígenos e 48 horas após o estímulo com mitógenos. O resultado de cada idoso foi expresso em função da média aritmética das contagens por minuto (cpm) das culturas em triplicata, acompanhadas de desvio padrão. O índice de proliferação linfocitária correspondeu ao c.p.m. estimulado/c.p.m. não estimulado. Valores aceitáveis para a proliferação linfocitária correlacionaram-se aos índices de proliferação linfocitária > 20. 


\subsection{Marcação de células e análise por citometria de fluxo (FACS)}

Células mononucleares de sangue periférico (PBMCs) obtidas frescas, foram analisadas por citometria de fluxo para a porcentagem de populações celulares CD3+, CD4+, CD8+, $C D 19^{+}$e $C^{2} 14^{+}$e para a expressão de marcadores de superfície CD25, CD69 e CD95. As células foram obtidas segundo método de gradiente de centrifugação por Ficoll a 950 X g por 20 minutos a temperatura ambiente. $\mathrm{O}$ anel da interface contendo as PBMCs foi lavado 3 vezes em PBS a $4^{\circ} \mathrm{C}$ e as células incubadas sob agitação com 1 $\mu \mathrm{g} / 10^{6}$ células com os anticorpos anti-CD3 FITC, anti-CD4 PE, anti-CD8 FITC, anti-CD19 FITC, anti-CD14 FITC, anti-CD25 PE, anti-CD69 FITC e anti-CD95 PE. O controle de células vivas foi conduzido nas amostras por meio da contra-coloração com iodeto de propídeo. Um mínimo de 10.000 células-eventos/amostra foram adquiridas dentro do gate de células vivas. Utilizamos o software CellQuest $^{\circledR}$ em um FACScalibur ${ }^{\circledR}$ (Becton-Dickinson).

\subsection{Determinação da produção de citocinas por ELISA}

PBMCs foram cultivadas numa concentração de $4,0 \times 10^{5}$ células/poço em triplicata em placas de 96 poços com fundo redondo (Costar Cambridge, MA) contendo $200 \mu$ de DMEM com 5\% soro humano 
$\mathrm{AB}+$ na presença de $5 \mu \mathrm{g} / \mathrm{ml}$ de PHA (PHA, Sigma Chemical Co.) durante 24 horas em estufa a $37^{\circ} \mathrm{C}$, com atmosfera de $10 \%$ de $\mathrm{CO}_{2}$ e saturada de umidade a 95\%. O sobrenadantes foram utilizados após 24 horas para a quantificação de IL-2 e 48 horas para a dosagem de IL-4, IL-8 e IFN- $\gamma$ após estímulo com PHA. Para a dosagem de IL-12, PBMCs foram cultivadas com $5 \mu \mathrm{g} / \mathrm{ml}$ de LPS durante 20 horas. Placas de 96 poços com fundo chato e de alta afinidade para EIA/RIA (Costar Cambridge, MA, EUA), foram sensibilizadas com anticorpo monoclonal e as detecções de IL-2, IL-4, IL-8, IL-12 e IFN- $\gamma$ foram realizadas de acordo com o protocolo especificado pelo fabricante (Pharmacia, Piscataway, NJ). Brevemente, anticorpos de captura foram utilizados para a sensibilização da placa na concentração e tempo especificados pelo fabricante. Após incubação, as placas foram lavadas quatro vezes com PBS-Tween 0,05\% (PBS, pH 7,4; 0,05\% de Tween 20; $0,01 \%$ de Thimerosal). A seguir estas foram submetidas ao bloqueio dos sítios não cobertos pelo anticorpo de captura com $100 \mu \mathrm{l} /$ poço de solução estéril de PBS contendo 5\% albumina sérica bovina (BSA, Sigma Chemical Co.) e mantidas duas horas à temperatura ambiente. Após quatro lavagens das placas com PBS-Tween $0,05 \%$, os sobrenadantes de cultura das amostras a serem testadas provenientes da proliferação de células mononucleares e a curva padrão com a citocina apropriada foram acrescidas aos poços (50 $\mu \mathrm{l} / \mathrm{poço})$ e incubadas duas horas à $37^{\circ} \mathrm{C}$. Seguida à lavagem de cada poço, cinco vezes com PBS-Tween 0,05\%, foi acrescido o anticorpo de detecção conjugado à biotina ( PharMigen, San Diego, CA) diluído em PBS-Tween 0,05\% e mantido durante duas horas à temperatura 
ambiente. Após serem efetuadas cinco lavagens com PBS-Tween 0,05\%, foi acrescida streptavidina marcada com peroxidase (Amersham, Arlingtong Heilghts, IL) diluída em PBS-Tween $0,05 \%$ durante 30 minutos à temperatura ambiente. Os poços foram lavados cinco vezes, sendo acrescida à solução o substrato contendo $0,03 \%$ de $\mathrm{H}_{2} \mathrm{O}_{2}$ e o cromógeno ABTS [2,2"-azino-bis(3- ethylbenzothiazoline-6-sulfonic acid, Sigma Chemical Co.)] dissolvido em tampão citrato $0,028 \mathrm{M} /$ fosfato de sódio 0,044M. Com o desenvolvimento da reação, avaliada pelo aparecimento de cor nos poços, a reação foi interrompida com a utilização de ácido cítrico 0,2 M e a absorbância determinada em leitor de ELISA (Molecular Devices , Mountain View, CA, EUA) e o programa Vectra que o acompanha na versão para computadores Apple/Macintosh, utilizando comprimento de onda de $405 \mathrm{~nm}$.

\subsection{Testes cutâneos de hipersensibilidade tardia}

A resposta de hipersensibilidade tardia para os antígenos candidina, tricofitina e para o PPD foi mensurada antes e após o procedimento cirúrgico. O procedimento consistiu em injetar a diluição adequada de cada um dos antígenos a serem testados, no volume de 0.1 $\mathrm{ml}$, usando uma seringa de insulina e uma agulha gauge 27 sob a epiderme do antebraço dos idosos. O nódulo formado para cada antígeno foi marcado de forma apropriada, e as leituras foram efetuadas 48 e 72 horas após a 
injeção dos antígenos. Foram considerados positivos os testes que corresponderam a um edema/eritema de pelo menos $4 \times 4 \mathrm{~mm}$ para candidina e tricofitina e $5 \times 5 \mathrm{~mm}$ para PPD, os quais foram mensurados através da medida do maior diâmetro transversal do nódulo palpável (MacLean,1988; Tellado-Rodriges et al.,1998; Kautor,1975).

\subsection{Anestésicos utilizados}

Os pacientes receberam durante o procedimento de anestesia, fentanil, propofol ou tiopental e midazolan.

\subsection{Locais de execução dos experimentos}

Os experimentos in vitro foram realizados no Laboratório de Imunologia Clínica do Departamento de Imunologia do Instituto de Ciências Biomédicas da Universidade de São Paulo-ICB IV- USP. O preenchimento dos questionários e a aplicação dos testes cutâneos de hipersensibilidade tardia foram realizados na enfermaria da Unidade de Valvopatia do Instituto do Coração-InCor. 


\subsection{Análise Estatística}

Para todas as nossas análises estatísticas, foi utilizado o software Graph pad Prism ${ }^{\circledR}$ (San Diego, CA). Devido ao fato de que nossas análises são realizadas para antes e depois da cirurgia do mesmo indivíduo, utilizamos o teste t-pareado. Para as análises do teste de hipersensibilidade tardia, assim como para os ensaios de linfoproliferação, utilizamos o teste two-way ANOVA. 


\section{RESULTADOS}

\subsection{Distribuição das variáveis epidemiológicas}

O estudo foi realizado a partir de uma amostra de 50 pacientes que foram submetidos à correção cirúrgica de valvulopatia cardíaca. Vinte e seis indivíduos eram do sexo feminino $(52,0 \%)$ e vinte e quatro do sexo masculino (48\%). A idade variou entre 65 e 83 anos, com a média de 71,3 anos ( $\pm 4,9$ anos). A média do índice de massa corpórea foi de $22,6 \mathrm{~kg} / \mathrm{m}^{2}$ $\left( \pm 2,6 \mathrm{~kg} / \mathrm{m}^{2}\right)$, com os valores variando entre 17,6 e $28,4 \mathrm{~kg} / \mathrm{m}^{2}$. Nenhum dos pacientes realizava qualquer atividade física regular. Nenhum dos pacientes foi diagnosticado como depressivo maior. Todos os pacientes receberam transfusão sanguínea com bolsas de sangue estocadas por um período menor do que 10 dias. O tempo médio de circulação extra-corpórea a que os pacientes ficaram submetidos foi de 95 minutos (55'- 144'). 


\subsection{Teste cutâneo de hipersensibilidade tardia}

\subsubsection{Teste cutâneo de hipersensibilidade tardia com candidina, PPD e tricofitina}

No intuito de avaliarmos possíveis alterações na imunidade celular de nossos pacientes após a realização da cirurgia de valva cardíaca, iniciamos nossos estudos através da análise dos testes cutâneos de hipersensibilidade tardia para candidina, PPD e tricofitina. Elegemos esses antígenos pelo fato de que uma grande porcentagem de indivíduos apresenta reação cutânea positiva para eles, evidenciando exposição prévia. Vale ressaltar que se trata de um teste simples de ser realizado e de grande valia na avaliação do componente celular da resposta imune.

Como podemos observar na figura 1, nossos pacientes não apresentaram diferença nas leituras dos testes quando estes foram realizados antes e depois da cirurgia para os antígenos tricofitina e candidina. Todavia, quando utilizamos o antígeno PPD, verificamos que houve uma redução estatisticamente significativa nos valores da mensuração dos nódulos formados. 


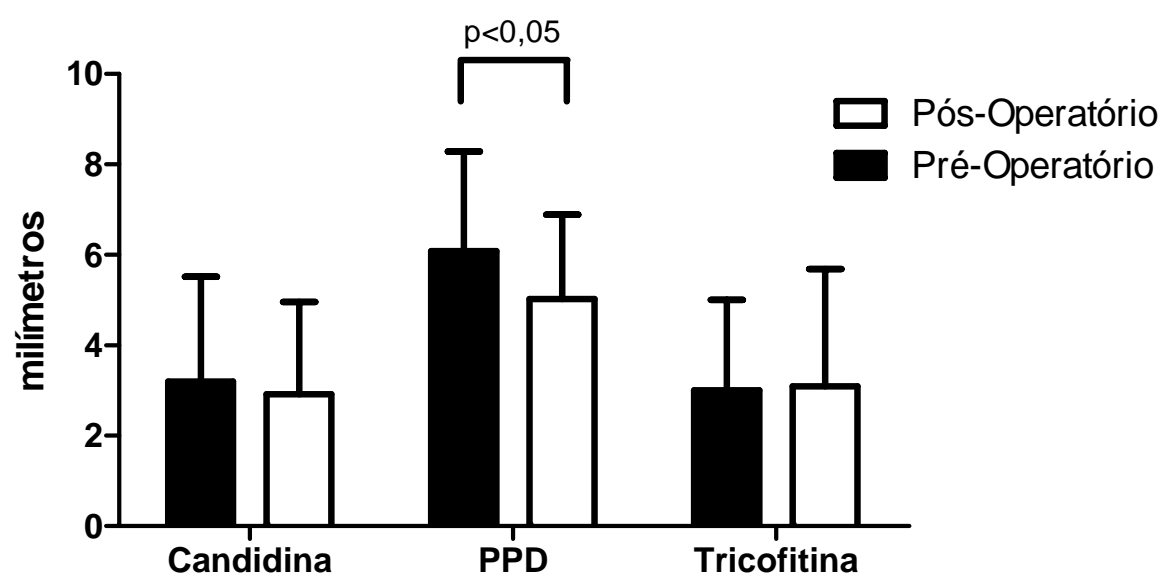

Figura 1. Teste cutâneo de hipersensibilidade tardia para candidina, PPD e tricofitina no pré e pós-operatório de valva cardíaca em idosos. Os indivíduos foram submetidos ao teste cutâneo de hipersensibilidade tardia para os antígenos citados 5-7 dias antes e depois da cirurgia. Gráficos representam média \pm DP. $n=50$. Two-way ANOVA. 


\subsection{Ensaios de linfoproliferação para mitógenos e antígenos}

\subsubsection{Linfoproliferação frente aos estímulos com Con A, PHA, PPD e TT}

No intuito de corroborarmos os dados observados através do teste de hipersensibilidade tardia, o qual pode evidenciar um comprometimento na resposta de linfócitos $T$, avaliamos também a capacidade linfoproliferativa de PBMCs estimulados in vitro. Utilizamos como estímulo, a PHA e a ConA, com conhecida capacidade de ativação policlonal, assim como os antígenos TT e PPD.

Sendo assim, como podemos observar na figura 2, nossos testes de hipersensibilidade tardia foram confirmados através deste ensaio. Como demonstrado através dos índices de estimulação, podemos observar uma resposta proliferativa mais intensa quando as culturas foram estimuladas com mitógenos, como esperado. Mais interessante notar que, PHA se mostrou como um estímulo mais potente do que a Con A. Quando fazemos as comparações das respostas linfoproliferativas antes e depois da cirurgia nos mesmos indivíduos, não observamos diferença entre os períodos, tanto para os antígenos como para os mitógenos. Tais resultados associados aos dados de hipersensibilidade nos demonstram que não há comprometimento da resposta celular em nossos indivíduos. 


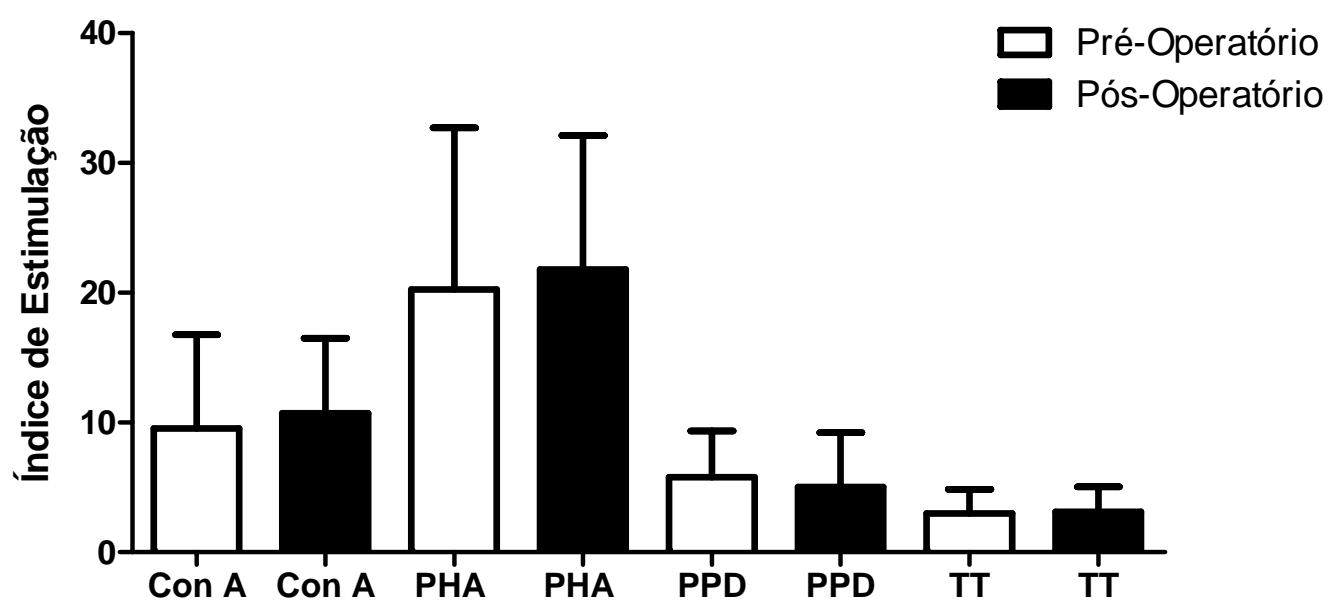

Figura 2. Ensaio de linfoproliferação frente aos mitógenos ConA e PHA e aos antígenos PPD e TT no pré e pós-operatório de cirurgia de valva cardíaca. PBMCs coletadas 5-7 dias antes e depois da cirurgia foram cultivadas e a resposta proliferativa avaliada 96 horas após o estímulo com antígenos e 48 horas após o estímulo com mitógeno. Dados apresentados como média \pm DP. $n=50$. Two-way ANOVA. 


\subsection{Ensaios de secreção de citocinas}

\subsubsection{Quantificação de IL-2 em sobrenadante de cultura de PBMCs}

Continuando nossos experimentos na busca por alterações da resposta imune desencadeadas pelo processo de cirurgia de valva cardíaca

em idosos, avaliamos também a capacidade de PBMCs em secretar citocinas após estimulação in vitro. Sendo a IL-2 uma citocina importante na viabilidade e proliferação de linfócitos T ( Amadori et al,1988) avaliamos sua produção in vitro após estimulação com PHA. Tal dado nos evidenciaria, um possível comprometimento na ativação das células $\mathrm{T}$ desencadeado pelo possível estresse gerado pela cirurgia.

De forma interessante, podemos observar na figura 3 que houve uma redução significativa na capacidade de secretar esta citocina quando as PBMCs foram obtidas 5-7 dias pós-cirurgia. Vale ressaltar que nossas análises foram feitas de forma pareada, evidenciando que essas reduções são individuais, ou seja, cada indivíduo apresentou uma reduzida secreção de IL-2 após a cirurgia, de forma independente do grupo como um todo. 


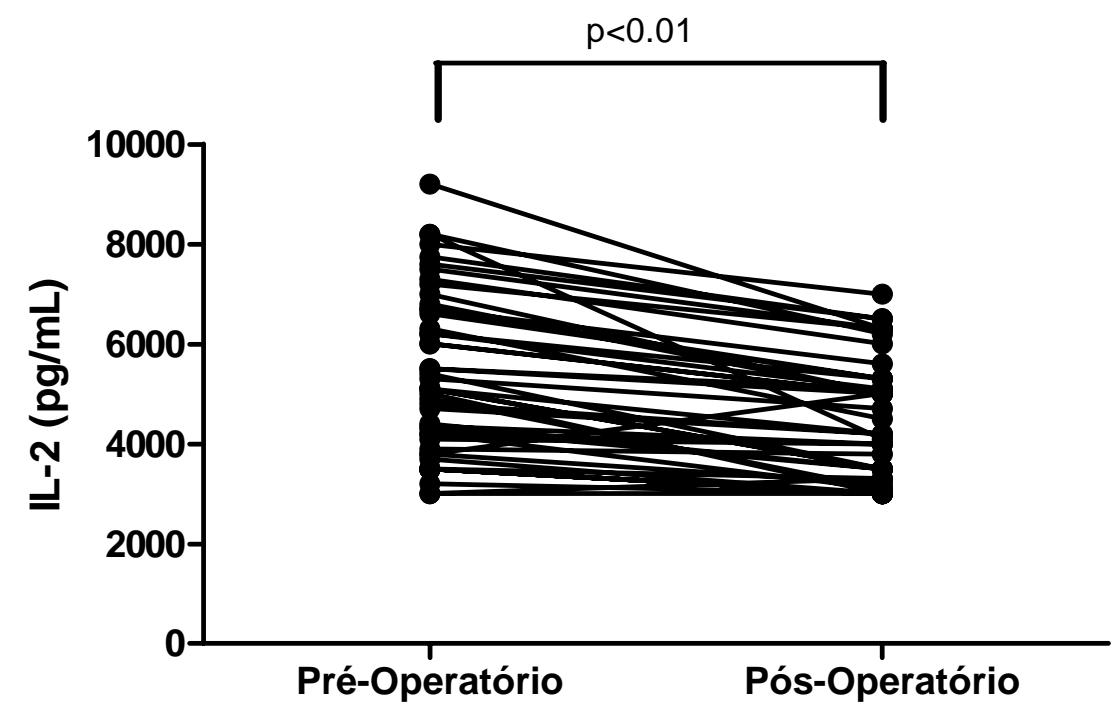

Figura 3. Quantificação de IL-2 em sobrenadante de cultura de PBMCs de idosos no pré e pós-operatório de cirurgia de valva cardíaca. PBMCs coletadas 5-7 dias antes e depois da cirurgia foram cultivadas e estimuladas com $5 \mu \mathrm{g} / \mathrm{ml}$ de PHA durante 24 horas. O sobrenadante foi coletado e a IL-2 quantificada por metodologia de ELISA. Teste t pareado. 


\subsubsection{Quantificação de IL-4 em sobrenadante de cultura de PBMCs}

Como observamos diferença na produção de IL-2, o que nos evidencia uma mudança na atividade de células T CD4 ${ }^{+}$, avaliamos também a secreção de IL-4. Tal dado pode nos ser útil no intuito de verificarmos uma possível mudança no balanço Th1 Vs Th2 em nossos pacientes.

De forma interessante, PBMCs de idosos obtidos após a cirurgia e estimuladas com PHA durante 48 horas produziram maiores quantidades de IL-4 quando comparamos com os dados do pré-operatório (Figura 4). Tal resultado nos leva a crer que há sim um possível desequilíbrio na rede de regulação da produção de citocinas nesses indivíduos. 


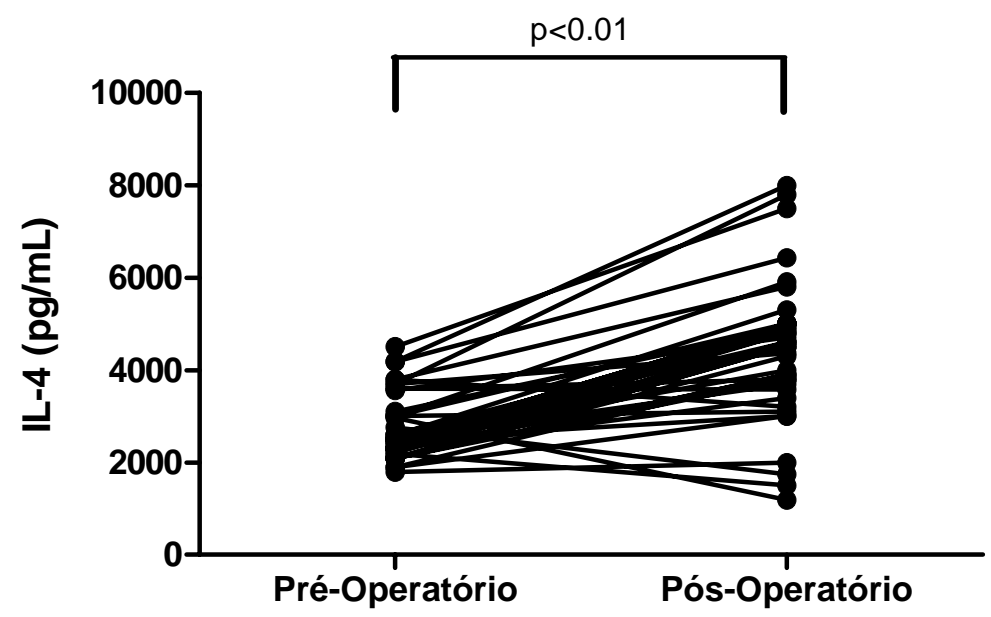

Figura 4. Quantificação de IL-4 em sobrenadante de cultura de PBMCs de idosos no pré e pós-operatório de cirurgia de valva cardíaca. PBMCs coletadas 5-7 dias antes e depois da cirurgia foram cultivadas e estimuladas com $5 \mu \mathrm{g} / \mathrm{ml}$ de PHA durante 48 horas. O sobrenadante foi coletado e a IL-4 quantificada por metodologia de ELISA. Teste t pareado. $(p<0,01)$. 


\subsubsection{Quantificação de IFN- $\gamma$ em sobrenadante de cultura de PBMCs}

Continuando com a possibilidade de que a cirurgia de valva cardíaca possa levar a uma alteração na produção de citocinas, como já observado para IL-2 e IL-4, avaliamos também a quantidade de IFN- $\gamma$ secretada por PBMCs estimulados in vitro. Vale ressaltar que esta, assim como a IL-4 são responsáveis pela manutenção e balanço das respostas de perfil Th1 e Th2 respectivamente.

Como demonstrado pela figura 5, observamos que as PBMCs obtidas após a cirurgia apresentam uma reduzida capacidade de secretar IFN- $\gamma$ após estimulação in vitro, quando comparadas ao período pré-operatório. Tal dado nos leva a crer que o ato cirúrgico neste grupo de idosos, leva a um desvio de resposta mais propenso a um perfil Th2, com aumento na secreção de IL-4 e diminuição no IFN- $\gamma$ e IL-2. 


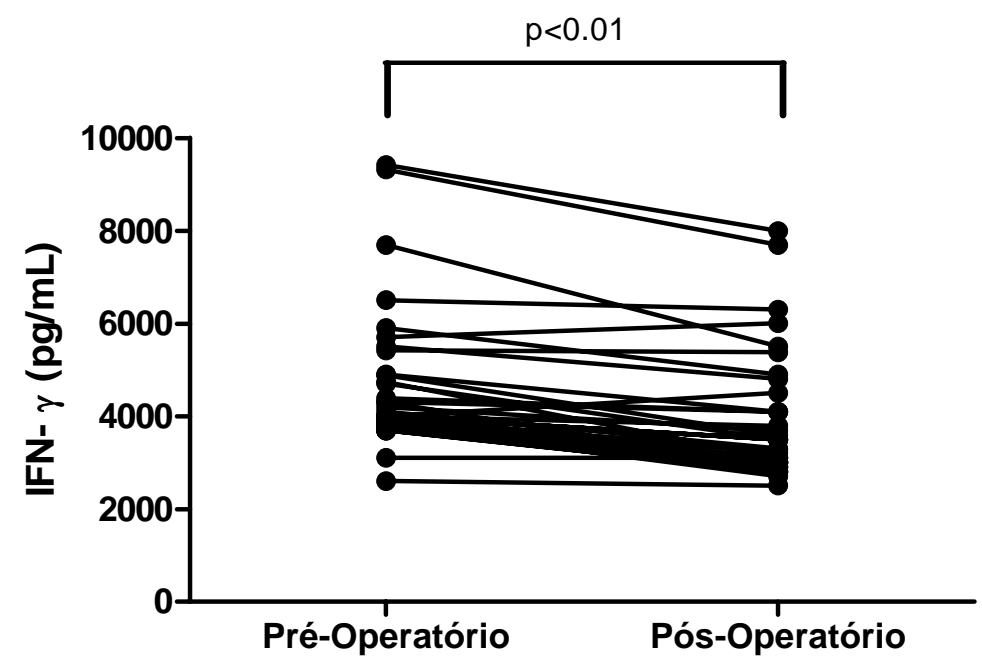

Figura 5. Quantificação de IFN- $\gamma$ em sobrenadante de cultura de PBMCs de idosos no pré e pós-operatório de cirurgia de valva cardíaca. PBMCs coletadas 5-7 dias antes e depois da cirurgia foram cultivadas e estimuladas com $5 \mu \mathrm{g} / \mathrm{ml}$ de PHA durante 48 horas. O sobrenadante foi coletado e o IFN$\gamma$ quantificado por metodologia de ELISA. Teste t-pareado. 


\subsubsection{Quantificação de IL-12 em sobrenadante de cultura de PBMCs}

Sendo que o desvio de resposta para um padrão Th1 é altamente dependente da produção de IL-12, associado ao fato de que observamos uma menor concentração de IFN- $\gamma$ nos sobrenadantes avaliados póscirurgia, avaliamos também a secreção desta citocina, tentando correlacionar os dados observados.

De fato, como ilustrado pela figura 6 , podemos observar que há uma menor secreção de IL-12 pelas células mononucleares obtidas dos indivíduos após a cirurgia quando estas são estimuladas in vitro com LPS. Tal dado corrobora nossa hipótese de que há algo como um desvio imune, onde observamos menos IFN- $\gamma$, provavelmente devido a uma menor produção de IL-12. 


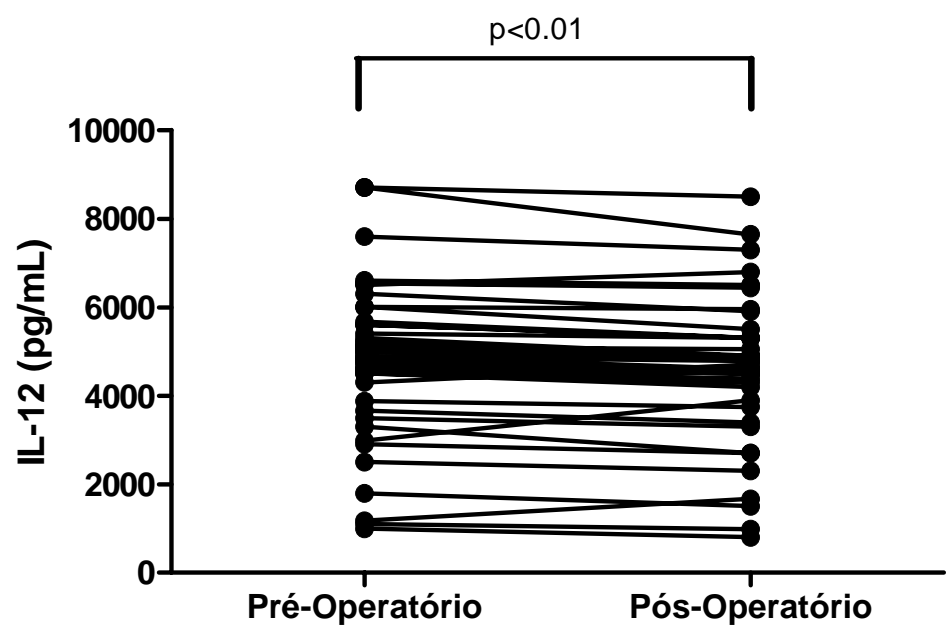

Figura 6. Quantificação de IL-12 em sobrenadante de cultura de PBMCs de idosos no pré e pós-operatório de cirurgia de valva cardíaca. PBMCs coletadas 5-7 dias antes e depois da cirurgia foram cultivadas e estimuladas com $5 \mu \mathrm{g} / \mathrm{ml}$ de LPS durante 20 horas. O sobrenadante foi coletado e a IL-12 quantificada por metodologia de ELISA. Teste t-pareado. 


\subsubsection{Quantificação de IL-8 em sobrenadante de cultura de PBMCs}

Sendo que o IFN- $\gamma$ também pode ser secretado por células NK, avaliamos a produção de IL-8, uma citocina sabidamente importante na ativação destas células. Além disso, se levarmos em consideração o importante papel desta população celular na resposta imune imediata, podemos considerar uma ferramenta interessante em nossos estudos. A figura 7 nos mostra que há um aumento significativo na produção de IL-8 quando as PBMCs obtidas pós-cirurgia são estimuladas in vitro com PHA. 


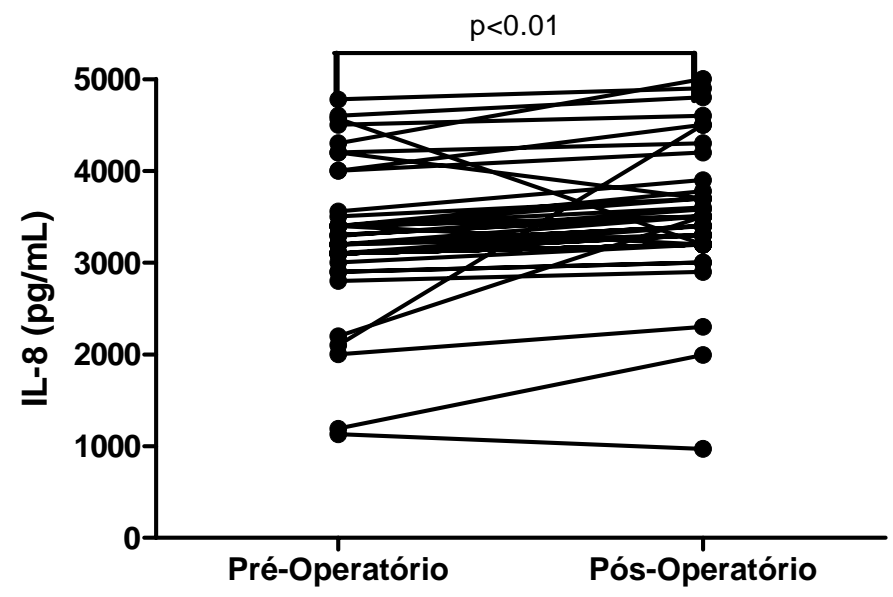

Figura 7. Quantificação de IL-8 em sobrenadante de cultura de PBMCs de idosos no pré e pós-operatório de cirurgia de valva cardíaca. PBMCs coletadas 5-7 dias antes e depois da cirurgia foram cultivadas e estimuladas com $5 \mu \mathrm{g} / \mathrm{ml}$ de PHA durante 48 horas. O sobrenadante foi coletado e a IL-8 quantificada por metodologia de ELISA. Teste t pareado. 
4.5. Análise da porcentagem de populações celulares e da expressão de marcadores de superfície celular através da citometria de fluxo

\subsection{1. $\mathrm{CD}^{+}$}

Como observamos diferenças interessantes na secreção de citocinas por PBMCs dos indivíduos idosos quando obtidas após a cirurgia de valva cardíaca, principalmente aquelas relacionadas às células $\mathrm{T}$, resolvemos avaliar possíveis alterações nas porcentagens destas e outras células no sangue periférico de nossos pacientes.

Sendo assim, iniciamos nossas análises através da população de células $\mathrm{T}$ totais $\mathrm{CD}^{+}$. De forma interessante, como demonstrado na figura 8 , nossos pacientes apresentaram uma expansão desta população no sangue periférico quando comparamos os diferentes períodos. Tal dado nos infere que, de alguma forma que esta cirurgia é capaz de ativar e expandir a população de células T. 


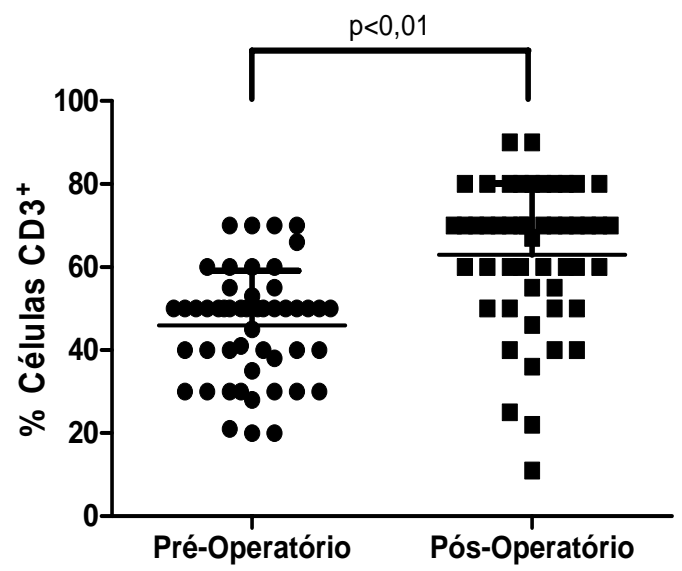

Figura 8. Análise por citometria de fluxo da porcentagem de células $\mathrm{T} C D 3^{+}$ no sangue periférico de indivíduos submetidos à cirurgia de valva cardíaca. PBMCs coletadas 5-7 dias antes e depois da cirurgia foram submetidas ao protocolo de marcação para citometria de fluxo de acordo com materiais e métodos. $\mathrm{n}=50$. Teste $\mathrm{t}$-pareado.

\subsection{2. $\mathrm{CD}^{+}$}

Após observarmos que houve um aumento na população total de células T no pós-operatório, resolvemos analisar qual tipo celular seria responsável por este aumento na porcentagem. Para isto, avaliamos a população de linfócitos T CD4 ${ }^{+}$. Como demonstrado na figura 9, observamos um aumento na porcentagem deste tipo celular no sangue periférico dos nossos idosos. 


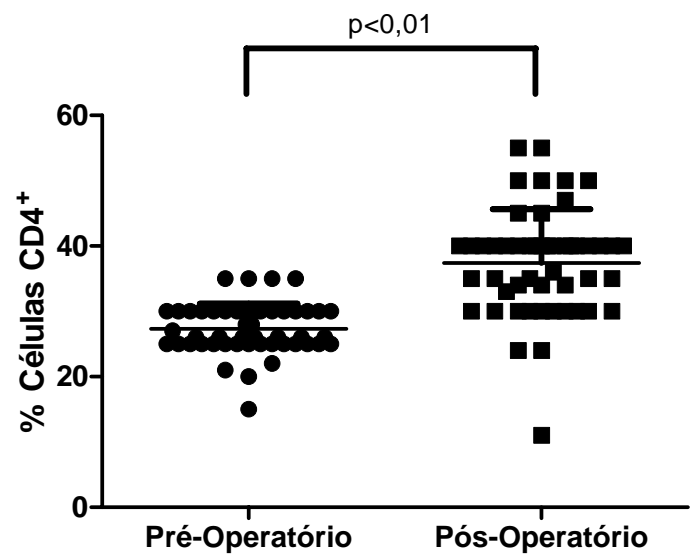

Figura 9. Análise por citometria de fluxo da porcentagem de células T CD4 no sangue periférico de indivíduos submetidos à cirurgia de valva cardíaca. PBMCs coletadas 5-7 dias antes e depois da cirurgia foram submetidas ao protocolo de marcação para citometria de fluxo de acordo com materiais e métodos. $n=50$. Teste t-pareado. 


\subsection{3. $\mathrm{CDB}^{+}$}

Conjuntamente à análise da população de células T CD4 ${ }^{+}$, estudamos os linfócitos $\mathrm{T} \mathrm{CD}^{+}$. Observamos uma dicotomia entre estas duas populações, e como demonstrado pela figura 10, houve uma diminuição na porcentagem desta população no pós-operatório. Vale ressaltar que por outro lado, observamos um aumento na porcentagem de células T CD4 ${ }^{+}$

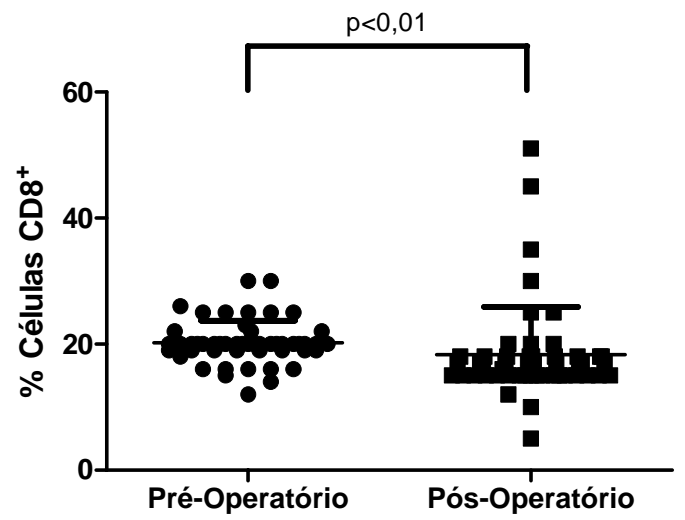

Figura 10. Análise por citometria de fluxo na porcentagem de células T CD8 ${ }^{+}$ no sangue periférico de indivíduos submetidos à cirurgia de valva cardíaca. PBMCs coletadas 5-7 dias antes e depois da cirurgia foram submetidas ao protocolo de marcação para citometria de fluxo de acordo com materiais e métodos. $n=50$. Teste $t$-pareado. 


\subsection{4. $\mathrm{CD}^{+} 9^{+}$}

Continuando nossas análises sobre alterações no perfil celular de PBMCs dos pacientes submetidos à cirurgia de valva cardíaca, resolvemos avaliar também a possibilidade de alteração na porcentagem de linfócitos B. Mesmo a despeito de já haver sido descrita pouca eu nenhuma alteração nesta população celular em indivíduos idosos. De forma esperada, como demonstra a figura 11, nossos dados não apontam para uma diferença na porcentagem de células B quando comparamos os dois períodos, ou seja, pré e pós-operatório.

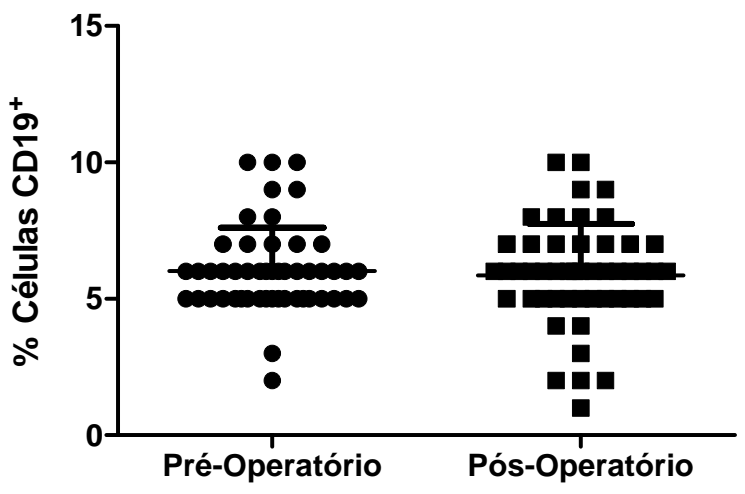

Figura 11. Análise por citometria de fluxo da porcentagem de células CD19 ${ }^{+}$ no sangue periférico de indivíduos submetidos à cirurgia de valva cardíaca. PBMCs coletadas 5-7 dias antes e depois da cirurgia foram submetidas ao protocolo de marcação para citometria de fluxo de acordo com materiais e métodos. $n=50$. Teste t-pareado. 


\subsection{5. $C D 14^{+}$}

A molécula CD14 é encontrada na superfície de monócitos e outras células sendo considerada como um marcador de células de origem mielóide. Este atua junto com o TLR-4 (Toll-like receptor 4), como receptor para lipopolissacarídeos. A literatura descreve um aumento na incidência de infecções em idosos, devido um comprometimento da resposta imune inerente desses indivíduos, e que também pode ocorrer quando os submetemos a atos cirúrgicos. Sendo assim, resolvemos avaliar a possibilidade de alteração na porcentagem desta população celular, baseado no fato de que é possível que o comprometimento observado em idosos seja devido a uma piora da resposta imune, agravada ainda mais pelo processo cirúrgico. Em nossos estudos, observamos como demonstrado na figura 12, um aumento na porcentagem de células que expressam CD14+ no período do pós-operatório. Tal aumento demonstra uma expansão desta população celular no sangue periférico dos indivíduos submetidos à cirurgia de valva cardíaca. 


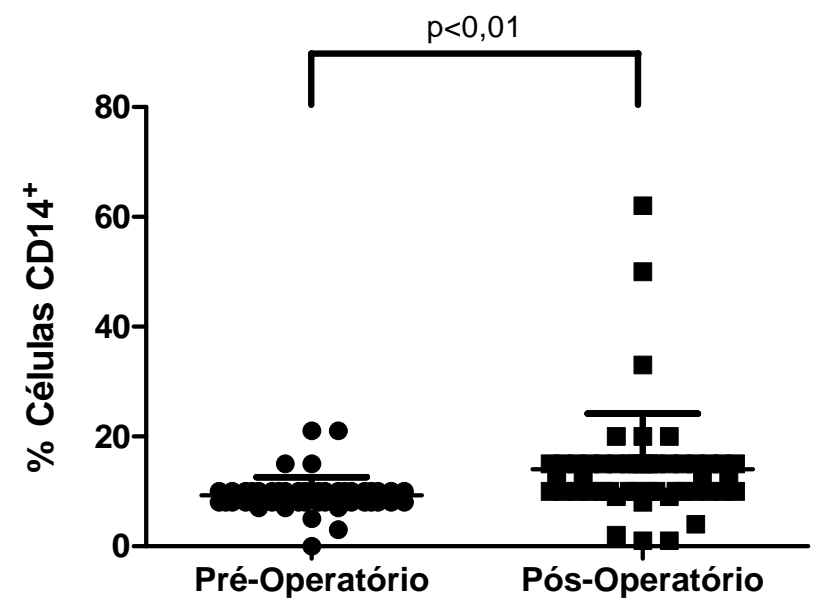

Figura 12. Análise por citometria de fluxo da porcentagem de células $C D 14^{+}$ no sangue periférico de indivíduos submetidos à cirurgia de valva cardíaca. PBMCs coletadas 5-7 dias antes e depois da cirurgia foram submetidas ao protocolo de marcação para citometria de fluxo de acordo com materiais e métodos. $\mathrm{n}=50$. Teste $\mathrm{t}$-pareado. 


\subsection{6. $\mathrm{CD}^{+} 5^{+}$}

Observarmos que houve uma diminuição da secreção de IL-2 e também da porcentagem de $\mathrm{CD}^{+}$no período do pós-operatório. Pensamos hipoteticamente que, a diminuição do $\mathrm{CD}^{+}$estaria associado com um aumento na apoptose. Como já descrito na literatura, existe uma associação entre o aumento da expressão de CD95 com a diminuição do CD25. Decidimos então avaliar a expressão de CD25 (cadeia alfa do receptor da IL2) entre os períodos pré e pós-operatório devido ao fato deste se tratar de um conhecido marcador de ativação de células T. Como demonstrado pela figura 13 observamos um aumento de células $C D 25^{+}$no pós-operátório. Tal dado nos demonstra que a cirurgia per se é capaz de induzir uma ativação do sistema imune. Isso baseado no fato de que nenhum de nossos pacientes desenvolveu infecção no pós-operatório.

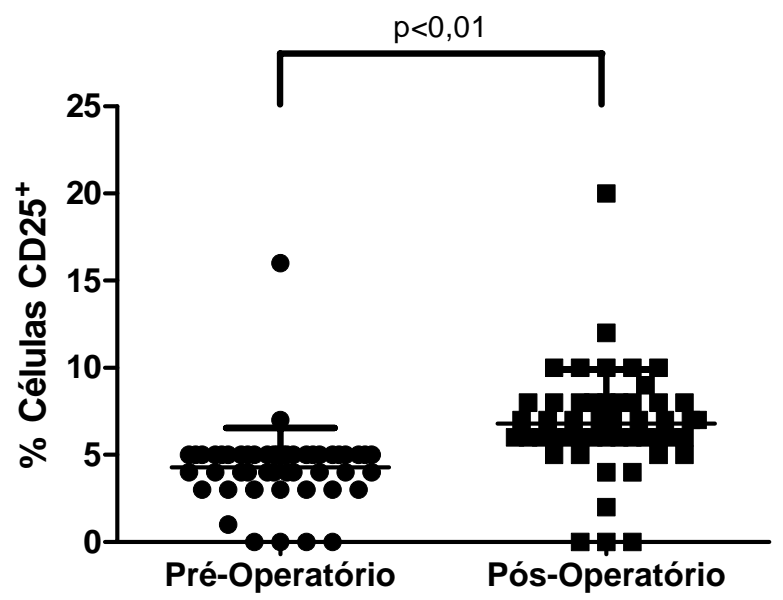

Figura 13. Análise por citometria de fluxo da porcentagem de células CD $25^{+}$ no sangue periférico de indivíduos submetidos à cirurgia de valva cardíaca. PBMCs coletadas 5-7 dias antes e depois da cirurgia foram submetidas ao protocolo de marcação para citometria de fluxo de acordo com materiais e métodos. $n=50$. Teste $t$-pareado. 


\subsection{7. $\mathrm{CD}^{+} 9^{+}$}

Além da análise da expressão de CD25, resolvemos também avaliar a expressão de outros marcadores de ativação celular. Elegemos então o CD69, por se tratar de um marcador de ativação precoce, evidenciando um processo agudo de ativação da resposta imune. Como podemos observar na figura 14, assim como para CD25, os PBMCs de nossos indivíduos apresentaram uma maior porcentagem de células positivas para esse marcador após a cirurgia..

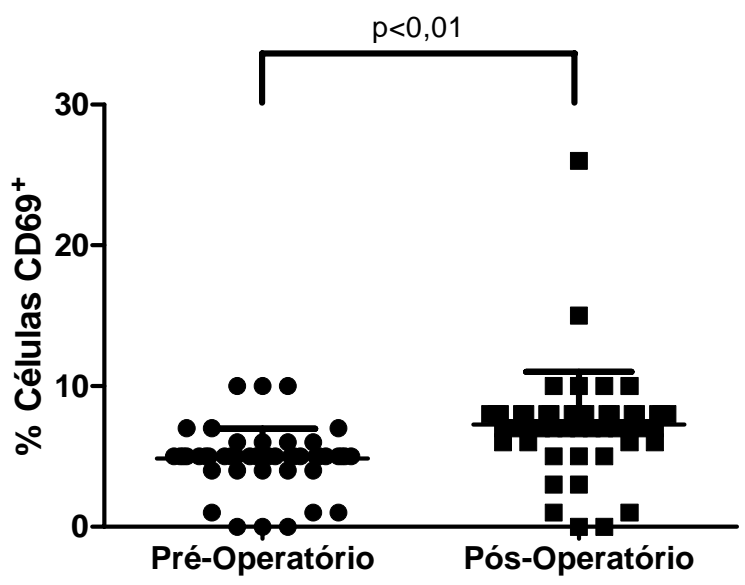

Figura 14. Análise por citometria de fluxo da porcentagem de células CD69 ${ }^{+}$ no sangue periférico de indivíduos submetidos à cirurgia de valva cardíaca. PBMCs coletadas 5-7 dias antes e depois da cirurgia foram submetidas ao protocolo de marcação para citometria de fluxo de acordo com materiais e métodos. $n=50$. Teste $t$-pareado. 


\subsubsection{CD95}

Já foi descrito que durante o envelhecimento humano existe uma progressiva linfopenia, tanto de células $\mathrm{T} \mathrm{CD}^{+}$e $\mathrm{CD}^{+}$, como revisto por Gupta et al., 2005. Uma das causas deste evento é a apoptose. Linfócitos T maduros ativados aumentam a expressão de CD95, tornando-os alvo da morte por apotose após o engajamento com seu ligante CD95L. Este é um mecanismo no qual o sistema imune tenta retornar ao seu estado basal, através da morte de clones ativados. Baseado nestes dados e ao observarmos que houve uma diminuição na porcentagem de células T CD8 ${ }^{+}$ no pós-operatório, observamos na figura 15 um aumento na porcentagem de células totais que expressam CD95. Tal dado nos leva a acreditar que a diminuição na porcentagem de células $\mathrm{T} \mathrm{CD}^{+}$positiva esteja realmente relacionada com a expressão deste marcador. Todavia, como não fizemos a análise específica da expressão de CD95 em células T CD8, não podemos afirmar com certeza se tal fenômeno é verdadeiro. 


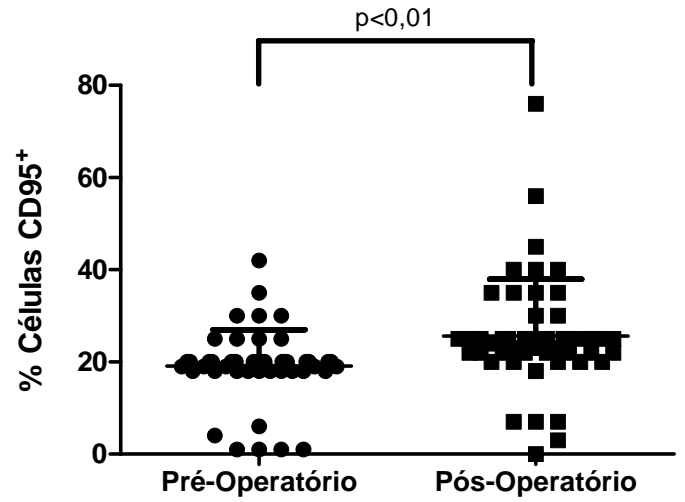

Figura 15. Análise por citometria de fluxo da porcentagem de células CD95 ${ }^{+}$ no sangue periférico de indivíduos submetidos à cirurgia de valva cardíaca. PBMCs coletadas 5-7 dias antes e depois da cirurgia foram submetidas ao protocolo de marcação para citometria de fluxo de acordo com materiais e métodos. $n=50$. Teste t-pareado. 


\section{DISCUSSÃO}

Tendo em vista as alterações do sistema imune descritas na literatura para pacientes acima de 65 anos de idade, focamos nossa análise em fatores que possam apresentar-se como marcadores de disfunção imune e, conseqüentemente nortear de alguma maneira a conduta clínica frente aos mesmos (Bauer, 2005; DelaRosa et al., 2006; Pawelec, 2006; Aw et al., 2007). Focamos nossos estudos naqueles indivíduos submetidos a uma cirurgia invasiva e de risco como a de correção de valva cardíaca.

Em um fenômeno chamado de imunosenescência, o sistema imune passa por um processo de envelhecimento durante o qual perde grande parte de sua capacidade funcional e regulatória. Processos infecciosos, tumores, doenças auto-imunes e cirurgias podem de alguma maneira alterar a evolução natural deste processo, acarretando em um comprometimento mais precoce da resposta imune.

Na prática clínica, a perda de resposta frente a antígenos encontrados universalmente pode ser interpretada como uma deficiência na função dos linfócitos T (Vukmanovic et al., 2006). Não observamos alteração estatisticamente significativa nos resultados encontrados nos testes cutâneos para candidina e tricofitina. Para o PPD, porém, encontramos uma diminuição na resposta no período do pós-operatório, a qual ocorreu em $58 \%$ dos idosos e que se demonstrou estatisticamente significativa. Contudo, em somente três deles houve uma diminuição na mensuração da leitura para menos do que $5 \times 5 \mathrm{~mm}$, ou seja, uma negativação do teste. Por isso, consideramos o teste cutâneo para o PPD inalterado e também, pelo 
fato de que não foi observada diferença para os outros dois antígenos. Uma diminuição na resposta da hipersensibilidade tardia é descrita como indicador de risco para pacientes submetidos à cirurgia evoluírem para sepse e acarretarem em um aumento da mortalidade (Maclean, 1988). Em nosso grupo, 05 pacientes apresentaram-se anérgicos aos antígenos testados, sinalizando, de alguma forma, que estes indivíduos poderiam apresentar alguma complicação infecciosa ou inflamatória. Todavia também acreditamos que é possível que estes indivíduos nunca tenham sido expostos a tais antígenos.

O apoio aos nossos resultados para os testes cutâneos foi não termos encontrado alteração, entre os períodos, nos ensaios de proliferação. Contudo, as divergências entre os nossos dados e os de outros autores podem estar associadas ao tempo da coleta do sangue até o processamento do mesmo. Para a realização dos testes in vitro, coletamos e processamos imediatamente o sangue, onde o mesmo foi mantido à temperatura ambiente. Conseqüentemente, evitou-se a liberação de fatores tóxicos, induzidos por estresse térmico, em pacientes cujas células já estão fragilizadas pela CEC, transfusão de sangue e anestésicos (Wu et al., 1991). O efeito imunossupressor causado tanto pela transfusão, como pelos anestésicos e pela CEC já não pode ser mais detectado através do teste de proliferação celular, realizado de 05 a 07 dias após o ato cirúrgico.

Analisamos as citocinas 2, 4 e o IFN- $\gamma$ como marcadores da dicotomia entre linfócitos Th1 e Th2, uma vez que este equilíbrio pode estar alterado nos pacientes idosos. O IFN- $\gamma$ é crucial na função e diferenciação de 
linfócitos Th1, e sua inibição pode levar ao aumento da secreção de IL-4 (DeKruyff et al., 1993). De forma interessante observamos que a cirurgia é capaz de induzir um declínio na secreção de IFN- $\gamma$ e IL-2 e um aumento da IL-4. No estudo de Naldini et al.,1999, houve um aumento da IL-10 em indivíduos também submetidos a CEC. Esta citocina controla a secreção de IFN- $\gamma$. O excesso de IL-10 pode induzir uma imunossupressão da resposta celular, podendo expor os pacientes a infecções.

Outros estudos corroboram com este achado, devido à influência dos anestésicos na secreção do IFN- $\gamma$ in vitro (Mosmann et al., 1989; Rizzo et al.,1991). É conhecido que os anestésicos influenciam o caminho ao qual uma resposta imune trilhará, privilegiando a síntese de IL-4. O tiopental, por exemplo, exerce um efeito inibitório nas citocinas do tipo Th1 (Galo et al., 1997) atuando principalmente em células $T$ de memória. A inibição da resposta Th1 pode, portanto, favorecer um aumento da IL-4 (resposta Th2) (Naldini et al.,1999; Corrêa-Sales et al.,1997).

Franke et al., 2006 ao estudarem pacientes submetidos a cirurgia cardíaca pertencentes a uma faixa etária diferente de nosso estudo, demonstraram que a diminuição do IFN- $\gamma$ é conseqüência da diminuição da síntese de IL-12. Estes dados são semelhantes aos nossos, uma vez que também encontramos uma diminuição da secreção da IL-12. Pensamos em um epifenômeno, onde a diminuição da secreção de IFN- $\gamma$ é conseqüência da atuação dos anestésicos associada à diminuição da síntese de IL-12.

A IL-12, uma das citocinas mais importantes na monta de uma resposta de padrão Th1, é um fator de crescimento que estimula linfócitos T 
citotóxicos e linfócitos NK a se proliferarem, estimula a diferenciação de linfócitos T CD4+ virgens para o subgrupo Th1 e estimula a diferenciação de linfócitos T CD8+ em linfócitos citotóxicos maduros funcionalmente ativos. É um fator importante como regulador da fase efetora das reações imunes celulares (Rizzo et al., 1992).

Outra importante interleucina pró-inflamatória é a IL-8. Esta é uma quimocina que atrai neutrófilos, basófilos e linfócitos. É produzida principalmente por leucócitos, fibroblastos, células endoteliais e epiteliais. Observamos um aumento da secreção da IL-8 no pós-operatório. Dado este semelhante encontrado por Franke et al., 2005, onde a secreção de IL-8 se manteve alta até o quinto dia do pós-operatório, podendo estar relacionado com a atuação da CEC. Vale ressaltar que, neste estudo, os pacientes não foram selecionados por idade. Dado diferente é visto por Galo et al.,1997, ao afirmarem que os anestésicos causam diminuição na secreção de IL-8. BrixChristensen et al.,1998 observaram que em pacientes submetidos a cirurgia cardíaca, sob anestesia com o fentanil independentemente da dose utilizada, não apresentaram alteração na produção de IL-8. Estes mesmos autores citaram que os níveis das citocinas, sob influência da CEC, retornam aos valores encontrados no pré-operatório em 1 a 3 dias.

O estudo de Siminelakis et al., 1996 demonstra que o procedimento da CEC leva a alterações fisiológicas que podem se prolongar até 72 horas após o seu término. E este mesmo estudo sugere que o trauma e o estresse cirúrgico levariam a uma depressão do número de células T CD4+ e CD8+. 
Em nossos estudos observamos uma expansão na população de células $\mathrm{T}$, aqui evidenciado pelo aumento na porcentagem de células $\mathrm{T} \mathrm{CD}^{+}$. Dados semelhantes foram encontrado por Pertillä et al., 1994, em pacientes também submetidos a CEC e que foram transfundidos.

Traill et al., 1995 demonstraram que o número de linfócitos T CD4+ e CD8+ está diminuído em idosos sem depressão psicológica. Além disso, a capacidade funcional destas células está alterada, como evidenciado pela baixa resposta ao estímulo pela PHA e ao estímulo com IL-2 (Ferrero et al.,1991; Amadori et al., 1998; Naldini et al.,1999). A diminuição desta resposta é devida à deficiência e/ou diminuição na produção de IL-2 por alterações ou defeitos na transdução de sinais mitogênicos vindos do receptor do linfócito T (TCR) (Fülöp et al., 2003). Em idosos, esta alteração na sinalização pode ser a mais importante causa do declínio da resposta imune celular mediada. Quando analisamos a porcentagem de células, observamos um aumento do CD4+ no pós-operatório. Dados diferentes foram constatados por Siminelakis et al., 1996, estudando pacientes acima de 60 anos, submetidos à cirurgia cardíaca com CEC, onde a porcentagem de CD4+ apresentou-se diminuída. Em nosso estudo, a porcentagem de CD8+ diminuiu. A expressão de CD 95 aumentou e o qual, mesmo sendo expresso em várias outras células, poderia ser caracterizado pela linfopenia de CD8+. Dado diferente do observado por Brand et al., 1997, em pacientes submetidos à cirurgia ortopédica, onde se utilizou os anestésicos tiopental, fentanil e isoflurano, os valores de CD8+ diminuíram durante a indução anestésica, retornando aos valores normais depois de iniciada a cirurgia. Tal 
resultado demonstra que, de alguma forma as células $C D 8^{+}$podem ser mais sensíveis à ação destas drogas, ou entrando em apoptose por ação de algum outro componente do ato cirúrgico ou pelo provável aumento nas infecções por se tratar de um estudo em idoso onde este fato torna-se mais comum. Mais interessante ressaltar que essa susceptibilidade pode estar relacionada ao aumento na expressão de CD95. Todavia, como não avaliamos a expressão deste marcador em populações específicas fica difícil chegarmos a alguma conclusão.

Também já foi demonstrado que a anestesia geral interfere com a resposta imune celular, e que em situações de estresse levam a uma supressão das funções imunes, sob a modulação do sistema neuroendócrino, através da atuação de esteróides, catecolaminas e endorfinas. Diversos anestésicos têm sido descritos, na literatura, como causadores da diminuição na expressão de CD14 em pós-operatórios e a conseqüente diminuição na capacidade celular em responder a lipopolissacárides bacterianos, e na liberação do antagonista do receptor de IL-1 (IL-1ra) (Galo et al., 1997). Encontramos um aumento na porcentagem de CD14, o que poderia de certa forma, explicar a ausência de processos infecciosos nos nossos idosos após a cirurgia. É possível que possa ter ocorrido uma diminuição da expressão de CD14, em nosso estudo, como demonstrou Kawasaki et al., 2001, mas como coletamos o sangue uma semana após a realização da cirurgia, encontramos estes valores de CD14.

Conseqüentemente, torna-se importante levar em consideração o efeito imunossupressor dos anestésicos, especialmente em pacientes nos quais o 
sistema imune encontra-se incapaz de reagir com a plasticidade necessária a eventos que deprimam a sua função (Nishina et al.,1998 ; Mikawa et al.,1998).

Não observamos alteração na porcentagem de CD19 (um marcador de células da linhagem B), enquanto o estudo de Rinder et al.,1997, ao comparar indivíduos com menos de 60 anos a outros com mais de 75 , ambos submetidos a CEC, demonstrou que nos dois grupos houve diminuição da expressão de CD19. Dados estes divergentes dos nossos haja vista que, pela atuação da CEC, em nosso trabalho tentamos minimizar estes efeitos através do aumento no período entre a cirurgia e a coleta do sangue.

Observamos aumento na expressão de CD25 ( cadeia alfa do receptor para IL-2), um marcador de ativação das células $\mathrm{T}$, o qual pode ter sido ocasionado por efeito dos anestésicos utilizados. Esta suposição é devido ao observado por Dennet et al., 2002, onde o aumento da expressão de CD95, o que também ocorreu em nosso estudo, está correlacionado com a diminuição da expressão de CD25, numa população de octagenários não submetidos a nenhum ato cirúrgico, no momento da coleta do sangue. Estes mesmos dados foram apresentados por Valle et al., 2004 ao compararem jovens doadores de sangue com idosos saudáveis. Ao observarmos um aumento na expressão de CD25, comprovamos a capacidade das células T destes indivíduos sofrerem ativação e manterem a resposta linfoproliferativa aos antígenos e mitógenos no pós-operatório. 
A expressão de CD69 apresentou-se aumentada, o que pode ser justificado pelos anestésicos utilizados que provocam a diminuição das células NK circulantes, aumentam o número de linfócitos B e linfócitos T CD8+. Solana et al., 2000, descrevem a diminuição da expressão de CD69 em idosos. Após o início da cirurgia, as células NK e CD8+ tendem a retornar ao valor normal (Brand et al., 1997). Nossos ensaios laboratoriais não foram efetuados em paralelo à observação do hemograma destes indivíduos, de forma que o nosso estudo se limitou ao número relativo e não absoluto de contagem de células.

Todos os nossos pacientes foram transfundidos com, em média, duas bolsas de sangue, as quais estiveram estocadas por um tempo máximo de dez dias. Optamos por levar em consideração este detalhe, pois o recebimento de sangue é mais um dos fatores que poderiam modular o sistema imune desses idosos, causando complicações ao aumentar os níveis plasmáticos de marcadores antiinflamatórios (Adamson, 2008; Koch et al., 2008). Num estudo realizado com pacientes acima de 18 anos de idade submetidos à cirurgia cardíaca e que receberam transfusão de sangue com bolsas estocadas por mais de duas semanas, foram observados um aumento significativo nas complicações e alterações no tempo de sobrevida no pós-operatório (Koch et al., 2008).

O estado nutricional de qualquer indivíduo tem papel crucial na manutenção da sua função imune, independentemente da idade cronológica (Krause et al., 1999; Fraker et al., 2000; Kemp et al., 2002). O grupo de idosos avaliados apresentou em média, um IMC de 22,6 kg/m2 $( \pm$ 2,6 
$\mathrm{kg} / \mathrm{m} 2$ ). Um IMC menor que 22, em idosos pode já configurar desnutrição (Marques et al., 2007). A desnutrição energético-protéica e conseqüente deficiência de micronutrientes constituem um problema comum no envelhecimento dos seres humanos (High et al., 1999). Esta desnutrição se origina de uma combinação de diferentes fatores, como a diminuição do poder sócio-econômico, isolamento social, síndromes de má absorção e alimentação inadequada (Beaumont et al., 1989). Supomos que nossos pacientes, através da análise do fator nutricional, tenham o sistema imune preservado.

A atividade física realizada regularmente favorece a manutenção de um sistema imune capaz (Han et al., 1999; Shor-Posner et al., 1999). Nenhum dos idosos realizava atividade física com regularidade. No estudo de Arai, 2004 ao comparar a atividade linfocitária de jovens sedentários e idosos sedentários com a de idosos que praticavam atividade física regular, houve nestes últimos uma resposta proliferativa de células $\mathrm{T}$ semelhante aos dos jovens.

O perfil psicológico do nosso grupo foi analisado através da aplicação do inventário Becker para depressão. Estudos demonstram existir uma grande porcentagem de idosos com doenças crônicas associadas a quadros depressivos (Belmaker et al., 2008). Este parâmetro é importante pela associação entre a depressão psicológica e a imune, especialmente em indivíduos com outros agravos à saúde (Miller et al., 2008; LinksKelley, 2004). Em idosos com estresse e/ou depressão, observa-se maior incidência de infecções, doenças auto-imunes e neoplasia (Guidi et al., 1998). 
Surpreendentemente, nenhum dos nossos idosos foi classificado como depressivo maior, o que, de alguma forma, nos sugere que há uma função imune preservada nos mesmos (Mcewen et al., 2007).

Demonstramos nestes parâmetros por nós estudados, que a maioria dos nossos achados são validados por outros estudos, mas analisamos um grupo com um comportamento bastante homogêneo, com ausência de muitos dos fatores que alterariam significativamente o sistema imune nestes idosos. Deparamos-nos com uma resposta imune bastante adequada, frente ao ato cirúrgico ao qual foram submetidos. 


\section{CONCLUSÕES}

Este estudo sugere que:

1. Idosos que se submeteram a cirurgia de valva cardíaca não apresentaram Índice de Massa Corpórea, na média, abaixo do valor normal.

2. Idosos que se submeteram a cirurgia de valva cardíaca não realizavam atividade física regular.

3. Idosos que se submeteram a cirurgia de valva cardíaca não apresentavam diagnóstico de depressão maior.

4. Idosos que se submeteram a cirurgia de valva cardíaca estiveram sob efeito da CEC por um tempo médio de 95 minutos.

5. Idosos que se submeteram a cirurgia de valva cardíaca receberam transfusão sanguínea com bolsas estocadas por um período menor do que 14 dias.

6. Idosos que se submeteram a cirurgia de valva cardíaca apresentaram, no pós-operatório, diminuição na secreção de IL-2 pelas PBMCs estimuladas in vitro.

7. Idosos que se submeteram a cirurgia de valva cardíaca apresentaram, no pós-operatório, aumento na secreção de IL-4 pelas PBMCs estimuladas in vitro.

8. Idosos que se submeteram a cirurgia de valva cardíaca apresentaram, no pósoperatório, diminuição na secreção de IL-12 pelas PBMCs estimuladas in vitro. 
9. Idosos que se submeteram a cirurgia de valva cardíaca apresentaram, no pós-operatório, aumento na secreção de IL-8 pelas PBMCs estimuladas in vitro.

10. Idosos que se submeteram a cirurgia de valva cardíaca apresentaram, no pós-operatório, diminuição na secreção de IFN- $\gamma$ pelas PBMCs estimuladas in vitro.

11. Idosos que se submeteram a cirurgia de valva cardíaca apresentaram um aumento percentual da população CD3+ no pós-operatório de valva cardíaca.

12. Idosos que se submeteram a cirurgia de valva cardíaca apresentaram um aumento percentual da população CD4+ no pós-operatório de valva cardíaca.

13. Idosos que se submeteram a cirurgia de valva cardíaca apresentaram uma diminuição percentual da população CD8+ no pós-operatório de valva cardíaca.

14. Idosos que se submeteram a cirurgia de valva cardíaca não apresentaram alteração no percentual da população $\mathrm{CD}_{19}{ }^{+}$no pósoperatório de valva cardíaca.

15. Idosos que se submeteram a cirurgia de valva cardíaca apresentaram um aumento percentual da expressão do marcador de superfície $\mathrm{CD}_{2} 5^{+}$no pós-operatório de valva cardíaca. 
16. Idosos que se submeteram a cirurgia de valva cardíaca apresentaram um aumento percentual da expressão do marcador de superfície $\mathrm{CD}^{+} 9^{+}$no pós-operatório de valva cardíaca.

17. Idosos que se submeteram a cirurgia de valva cardíaca apresentaram um aumento percentual da população $\mathrm{CD}_{1} 4^{+}$no pós-operatório de valva cardíaca.

18. Idosos que se submeteram a cirurgia de valva cardíaca não apresentaram alteração na leitura do teste cutâneo de hipersensibilidade tardia para PPD.

19. Idosos que se submeteram a cirurgia de valva cardíaca não apresentaram alteração na leitura do teste cutâneo de hipersensibilidade tardia para tricofitina.

20. Idosos que se submeteram a cirurgia de valva cardíaca não apresentaram alteração na leitura do teste cutâneo de hipersensibilidade tardia para candidina.

21. Idosos que se submeteram a cirurgia de valva cardíaca não apresentaram alteração no índice de estimulação obtido no ensaio de proliferação, utilizando-se a PHA, após o ato cirúrgico.

22. Idosos que se submeteram a cirurgia de valva cardíaca não apresentaram alteração no índice de estimulação obtido no ensaio de proliferação, utilizando-se a Con A, após o ato cirúrgico.

23. Idosos que se submeteram a cirurgia de valva cardíaca não apresentaram alteração no índice de estimulação obtido no ensaio de proliferação, utilizando-se PPD, após o ato cirúrgico. 
24. Idosos que se submeteram a cirurgia de valva cardíaca não apresentaram alteração no índice de estimulação obtido no ensaio de proliferação, utilizando-se o TT, após o ato cirúrgico. 
7. Anexos

7.1. Anexo A: Termo de consentimento

Termo de consentimento esclarecido

HOSPITAL DAS CLÍNICAS

DA FACULDADE DE MEDICINA DA UNIVERSIDADE DE SÃO PAULO

TERMO DE CONSENTIMENTO PÓS -INFORMAÇÃO

I - DADOS DE IDENTIFICAÇÃO DO SUJEITO DA PESQUISA OU

RESPONSÁVEL LEGAL

1. NOME DO PACIENTE.

DOCUMENTO DE IDENTIDADE $\mathrm{N}^{\circ}$ :

..SEXO: M [ ] F [ ]

DATA NASCIMENTO..........................

ENDEREÇO

BAIRRO: $\mathrm{N}^{\circ}$. APTO:

CEP: CIDADE

2.RESPONSÁVEL LEGAL

NATUREZA (grau de parentesco, tutor, curador etc.)

DOCUMENTO DE IDENTIDADE $\mathrm{N}^{\circ}$ :

ENDEREÇO

BAIRRO: ..SEXO: M [ ] F [ ]

CEP: CIDADE

APTO: TELEFONE: DDD ( )

II - DADOS SOBRE A PESQUISA CIENTíFICA

1. TÍTULO DO PROTOCOLO DE PESQUISA: “Avaliação imunológica de idosos no pré e pós-operatório de correção de valvulopatia cardíaca”

PESQUISADOR: Prof Dr. Luiz Vicente Rizzo

CARGO/FUNÇÃO: Professor Associado INSCRIÇÃO CONSELHO REGIONAL : 93223

UNIDADE DO HCFMUSP: Departamento de Imunologia Instituto de Ciências Biomédicas - USP - ICB IV.

3. AVALIAÇÃO DO RISCO DA PESQUISA: RISCO MÍNIMO

(probabilidade de que o indivíduo sofra algum dano como consequência imediata ou tardia do estudo)

4. DURAÇÃO DA PESQUISA: 2 anos 


\section{III - REGISTRO DAS EXPLICAÇÕES DO PESQUISADOR AO PACIENTE OU SEU REPRESENTANTE LEGAL SOBRE A PESQUISA, CONSIGNANDO:}

1. justificativa e os objetivos da pesquisa: $\mathrm{O}$ (a) senhor(a) está sendo convidado a participar de uma pesquisa que quer avaliar o sistema de defesa que está no seu sangue e que o defende de vírus e bactérias que causam infecções no nosso corpo. Faremos esta pesquisa colhendo sangue da veia de um de seus braços, e um teste com três injeções na sua pele com produtos que também servem para mostrar como o seu sistema de defesa está funcionando. Com isso queremos encontrar alterações que indiquem para o seu médico que ele deve ter algum cuidado especial para que não apareçam infecções depois de qualquer cirurgia em pessoas da mesma idade que a sua.

2. procedimentos que serão utilizados e propósitos, incluindo a identificação dos procedimentos que são experimentais: $\mathrm{O}(\mathrm{a}) \operatorname{sr}(\mathrm{a})$ fará um teste que é feito no mundo todo, este teste se chama teste cutâneo e nós o faremos aplicando 3 injeções na pele do lado de dentro do seu ante-braço e após três dias iremos olhar se apareceram algumas alterações no local da injeção que podem ser "caroçinhos" avermelhados e que também podem coçar. Este teste nos ajuda a avaliar como o seu sistema de defesa está funcionando contra as infecções. Também colheremos sangue da veia do seu braço para estudos em laboratório que irão avaliar o seu sistema de defesa contra vírus e bactérias.

3. desconfortos e riscos esperados; desconforto da picada da agulha, pode aparecer mancha roxa no local da retirada de sangue, e pode surgir pequena inflamação dolorosa nas injeções dos testes na pele

4. benefícios que poderão ser obtidos; Os pacientes e os voluntários não terão benefícios diretos da pesquisa.

5. procedimentos alternativos que possam ser vantajosos para o indivíduo: não há.

\section{IV- ESCLARECIMENTOS DADOS PELO PESQUISADOR SOBRE GARANTIAS DO SUJEITO DA PESQUISA:}

1. acesso, a qualquer tempo, às informações sobre procedimentos, riscos e benefícios relacionados à pesquisa, inclusive para dirimir eventuais dúvidas.

2. liberdade de retirar seu consentimento a qualquer momento e de deixar de participar do estudo, sem que isto traga prejuízo à continuidade da assistência.

3. salvaguarda da confidencialidade, sigilo e privacidade.

4. disponibilidade de assistência no HCFMUSP, por eventuais danos à saúde, decorrentes da pesquisa. 
5. viabilidade de indenização por eventuais danos à saúde decorrentes da pesquisa.

\section{V.INFORMAÇÕES DE NOMES, ENDEREÇOS E TELEFONES DOS RESPONSÁVEIS PELO ACOMPANHAMENTO DA PESQUISA, PARA CONTATO EM CASO DE INTERCORRÊNCIAS CLÍNICAS E REAÇÕES ADVERSAS.}

Dr.Luiz Vicente Rizzo 3069-6225

Irina Ewers 3069.6098

VI. OBSERVAÇÕES COMPLEMENTARES:

\section{VII - CONSENTIMENTO PÓS-ESCLARECIDO}

Declaro que, após convenientemente esclarecido pelo pesquisador e ter entendido o que me foi explicado, consinto em participar do presente Protocolo de Pesquisa

São Paulo,....... de......................... de $200 \ldots$.

$\overline{\text { assinatura do sujeito da pesquisa ou responsável legal }}$

assinatura do pesquisador

(carimbo ou nome legível)

7.2. Anexo B: Comissão de ética CAPPesq 


\section{APROVAÇÃO}

A Comissäo de Étrica para Análise de Prǫ̣etos de Pesquisa CAPPesq da Bireforia Clírica do Hospital das Clínicas e da Faculdade de Medicina da Universidade de Săo Paulo, em sessăo de 08.02.06, APROVCU a Protocolo de Pesquisa $n^{\circ}$ 015/06, intitulado: "Avaliaçäo da resposta imune em pacientes com idade superior a 65 anos submetidos a cirurgia cardíaca." apresentado pelo Departamento de CLINICA MÉDICA, inclusive o Termo de Consentimento Livre e Esclarecido.

Cabe ao pesquisador elaborar e apresertar à CAPPesq, os relatórios porciais e final sobre a pesquisa (Resolução do Corselho Nacional de Saúde $n^{\circ} 196$, de $10,10,1996$, inciso IX.2, letra ${ }^{\circ} c^{\circ}$ ).

Pesquisador(J) Responsável: Rrof. Dr. Luiz Vicente Rizzo

Pesquisodor ia) Executantei Dra. Irina Ewers

CAPPesq, 08 de fevereiro de 2006.

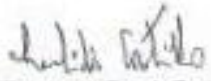

PROF, OR, EUCLIDES AYRES DE CASTILHO

Presidente da Comissōo de Ética para Análisé de Projetos de Pesquisa

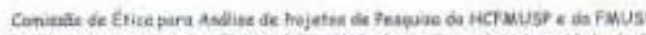

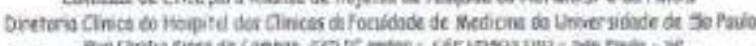

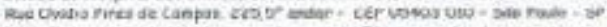

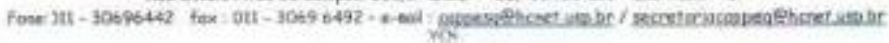


7.3. Anexo C: Inventário Becker de depressão (Determinação do perfil psicológico)

Este questionário consiste em 21 grupos de afirmações. Depois de ler cuidadosamente cada grupo, faça um círculo em torno do número $(0,1,2$ ou 3) diante da afirmação, em cada grupo, que descreve melhor a maneira como você tem se sentido nesta semana, incluindo hoje. Se várias afirmações num grupo parecerem se aplicar igualmente bem, faça um círculo em cada uma. Tome o cuidado de ler todas as afirmações, em cada grupo, antes de fazer a sua escolha.

1. Tristeza:

(0) Não me sinto triste.

(1) Eu me sinto triste.

(2) Estou sempre triste e não consigo sair disso.

(3) Estou tão triste ou infeliz que não consigo suportar.

2. Pessimismo:

(0) Não estou especialmente desanimado quanto ao futuro.

(1) Eu me sinto desanimado quanto ao futuro.

(2) Acho que nada tenho a esperar. 
(3) Acho o futuro sem esperança e tenho a impressão de que as coisas não podem melhorar.

3. Fracassos do Passado:

(0) Não me sinto um fracasso.

(1) Acho que fracassei mais do que uma pessoa comum.

(2) Quando olho para trás, na minha vida, tudo o que posso ver é um monte de fracassos.

(3) Acho que, como pessoa, sou um completo fracasso.

4. Perda de Prazer:

(0) Tenho tanto prazer em tudo como antes.

(1) Não sinto mais prazer nas coisas como antes.

(2) Não encontro um prazer real em mais nada.

(3) Estou insatisfeito ou aborrecido com tudo.

5. Sentimento de Culpa:

(0) Não me sinto especialmente culpado.

(1) Eu me sinto culpado às vezes.

(2) Eu me sinto culpado na maior parte do tempo.

(3) Eu me sinto sempre culpado. 
6. Sentimento de Punição:

(0) Não acho que esteja sendo punido.

(1) Acho que posso ser punido.

(2) Creio que vou ser punido.

(3) Acho que estou sendo punido.

7. Falta de amor próprio:

(0) Não me sinto decepcionado comigo mesmo.

(1) Estou decepcionado comigo mesmo.

(2) Estou enojado de mim.

(3) Eu me odeio.

8. Auto-crítica:

(0) Não me sinto de qualquer modo pior que os outros.

(1) Sou crítico em relação a mim devido a minhas fraquezas ou meus erros.

(2) Eu me culpo sempre por minhas falhas.

(3) Eu me culpo por tudo de mal que acontece. 
9. Desejo ou pensamentos suicidas:

(0) Não tenho quaisquer idéias de me matar.

(1) Tenho idéias de me matar, mas não as executaria.

(2) Gostaria de me matar.

(3) Eu me mataria se tivesse oportunidade.

10 .Choro:

(0) Não choro mais que o habitual.

(1) Choro mais agora do que costumava.

(2) Agora, choro o tempo todo.

(3) Costumava ser capaz de chorar, mas agora não consigo mesmo que o queira.

11. Agitação:

(0) Não sou mais agitado do que de costume.

(1) Estou mais agitado do que costumo ser.

(2) Atualmente me sinto agitado o tempo todo.

(3) Estou tão agitado que não consigo parar de fazer as coisas. 
12. Perda de Interesse:

(0) Não perdi o interesse nas outras pessoas.

(1) Interesso-me menos do que costumava pelas outras pessoas.

(2) Perdi a maior parte do meu interesse nas outras pessoas.

(3) Perdi todo o meu interesse nas outras pessoas.

13. Indecisão:

(0) Tomo decisões mais ou menos tão bem como em outra época.

(1) Adio minhas decisões mais do que costumava.

(2) Tenho maior dificuldade em tomar decisões do que antes.

(3) Não consigo mais tomar decisões.

14. Inutilidade:

(0) Não me sinto inútil.

(1) Não me sinto inútil de modo diferente do que sentia.

(2) Me sinto mais inútil quando me comparo com outras pessoas.

(3) Me sinto terrivelmente inútil. 
15. Perda de Energia:

(0) Tenho tanta energia quanto antes.

(1) Tenho menos energia do que costumava.

(2) Não tenho energia suficiente para fazer as coisas.

(3) Não tenho energia para fazer qualquer coisa.

16. Mudanças no Sono:

(0) Não vejo mudanças no sono .

(1) Durmo mais do que o normal /1b Durmo menos do que o normal.

(2) Durmo muito mais do que o normal/2b Durmo muito menos do que o normal.

(3) Durmo quase o dia todo /3b Acordo 1 ou 2 horas antes e não consigo mais dormir.

17. Irritabilidade:

(0) Não fico mais irritado que de hábito.

(1) Fico irritado com mais facilidade do que costumava.

(2) Sinto-me irritado ao fazer quase qualquer coisa.

(3) Estou irritado demais para fazer qualquer coisa. 
18. Mudanças de Apetite:

(0) Meu apetite não está pior do que de hábito.

(1) Meu apetite não é tão bom quanto costumava ser.

(2) Meu apetite está muito pior agora.

(3) Não tenho mais nenhum apetite.

19. Dificuldade de Concentração:

(0) Posso me concentrar como antes.

(1) Não consigo me concentrar tão bem quanto antes.

(2) É difícil manter a concentração por muito tempo.

(3) Não consigo me concentrar de jeito nenhum.

20. Cansaço e Fadiga:

(0) Eu não sou mais cansado ou fatigado do que normalmente fui.

(1) Eu fico cansado ou fatigado mais facilmente do que costumava ficar

(2) Eu me sinto tão cansado ou fatigado para fazer muitas das coisas que normalmente fazia.

(3) Eu me sinto tão cansado ou fatigado para fazer a maioria das coisas que eu que costumava fazer. 
21. Perda de Interesse Sexual:

(0) Não tenho observado qualquer mudança recente em meu interesse sexual.

(1) Estou menos interessado por sexo que costumava.

(2) Estou bem menos interessado em sexo atualmente.

(3) Perdi completamente o interesse por sexo.

7.4. Anexo D: Avaliação da realização de atividade física

a)baixa: não realizo nem trabalhos domésticos

b)moderada: realizo trabalhos domésticos regulares, caminhadas não regulares

c)alta: realizo atividade física regular fora da rotina habitual pelo menos 2 vezes/semana/30 minutos 


\section{REFERÊNCIAS BIBLIOGRÁFICAS}

Abacilar F, Dogan OF, Duman U, Ucar I, Demircin M, Ersov U, Dogan R, Boken E.The changes and effects of the plasma levels of tumor necrosis factor after coronary artery bypass surgery with cardiopulmonary bypass. Heart Surg Forum. 2006; 9(4):E703-9.

Abdalla LA, Piegas LS,Timermam S et al. Manuseio cirúrgico da válvula aórtica em pacientes acima de 70 anos. Arq. Bras Cardiol. 1992; 58:453-5.

Adamson JW. New blood, old blood or no blood? N Engl J Med. 2008; march 20,358;12.

Amadori A, Zanovello P, Cozzi E. Study of some early immunological parameters in aging humans. Gerontology. 1998; 34:277.

Arai $\mathrm{MH}$. Papel da atividade física regular realizada durante vários anos na função imune do idoso. 2004; LILACS.

Aw D, Silva AB, Palmer DB. Immunosenescence: emerging challenges for an ageing population. Immunology. Review article 2007; 120, 435-446.

Banchereau J, Stenman RM. Dendritic cells and the control of immunity [review]. Nature 1998;392:245-52.

Banchereau J, Briere F, Caux C, Davoust J, Lebecque S, Liu YJ et al. Immunobiology of dendritic cells. Annu Rev Immunol. 2000;18:767-811.

Bauer ME. Stress, glucocorticoids and ageing of the immune system. Strees. 2005; Mar; 8(1):69-83. 
Beaumont D, Lehmann AB, James OFW. Protein turnover in malnourished elderly subjects: the effects of referring. Age Ageing. 1989; 18(4): 235-40.

Belmaker RH, Agam G. Major Depressive Disorder. Review article. N Engl J Med. 2008; 55-68.

Bonagura VR, Hatam L, Devoti J, Zeng F, Steinberg BM. Recurrent respiratory papillomatosis: altered CD8( +) T -cell subsets and $T(H) 1 / T(H) 2$ cytokine imbalance. Clin Immunol. 1999; 93:302.

Borrego F, Alonso MC. NK phenotypic markers and IL-12 response in NK cells from elderly people. Exp Gerontol. 1999; 34(2):253-65.

Brand JM, Kjirchner H, Poppe C, Schmucker P. The effects of general anesthesia on human peripheral immune cell distribution and cytokine production. Clin Immunol Immunopatho. 1997;183:190.

Brix-Cristensen V, Tonnesen E. Effects of anaesthesia based on high versus low doses of opioids on the cytokine and acute-phase protein responses in patients undergoing cardiac surgery. Acta Anaesthesiol. 1998; 42:63.

Bruunsgaard H, Jensen MS, Schjerling P, Halkjaer-Kristensen J, Ogawa K, Skinhoj P, Pedersen BK. Exercise induces recruitment of lymphocytes with an activated phenotype and short telomeres in young and elderly humans. Life Sci. 1999; 65(24):2623-33.

Cella M, Sallusto F, Lanzavecchia A. Origin, maturation and antigen presenting function of dendritic cells. Curr Opin Immunol. 1997; 9:10-16.

Corrêa-Sales C, Tosta CE, Rizzo LV. The effects of anesthesia with thiopental on T lymphocyte responses to antigen and mitogens in vivo and in vitro. Int J Immunopharmac. 1997; Vol.19.No.2,pp.117-128. 
Delarosa O, Pawelec G, Peralbo E, Wikby A, Mariani E, Moncchegiani E, Tarazona R, Solana R. Immunological biomarkers of ageing in man: changes in both innate and adaptive immunity are associated with health and longevity. Biogerontology. 2006;7(5-6):471-81.

De Martinis M, Franceschi C, Monti D, Ginaldo L. Apoptosis remodeling in immunosenescence: implications for strategies to delay ageing. Curr Med Chem. 2007;14(13):1389-97.

DeKruyff RH, Rizzo LV, Umetsu DT. Induction of immunoglobulin synthesis by CD4+ T cell clones. Semin Immun. 1993; 5,421-430.

Dennett NS, Barcia RN, McLeod JD. Age associated decline in CD25 and CD28 expression correlate with an increased susceptibility to CD95 mediated apoptosis in T cells. Exp Gerontol. 2002; Jan-Mar; 37(2-3): 271-83. Faist E, Markewitz A, Fuchs D et al: Immunomodulatory therapy with thymopentin and indomethacin. Successful restoration of interleukin-2 synthesis in pacients undergoing major surgery. Ann Surg. 1991; 214:264275.

Ferrero EM, Bianchi AE. Age-related changes in interleukin 2 responsiveness of resting and activated human mononuclear cells. Haematologica 1991 Jan-Fev 76(1):14-9.

Fraker JP, King LE, Laakko T, Vollmer TL. The dynamic link between the integrity of the immune system and zinc status. J Nutr. 2000; 130(5S Suppl): S1399-406. 
Franceschi C, Monti D, Barbieri D. Sucessful immunosenescence and the remodelling of immune responses with ageing. Nephrol Dial Transpl. 1996; 11 Suppl 9:18-25.

Franke A, Lante W, Fackeldey V, Becker HP, Kuring E, Zoller LG, Weinhold C, Maekewitz A. Pro-inflammatory cytokines after different kinds of cardiothoracic surgical procedures: is what we see what we know? Euro $\mathrm{J}$ Cardiothorac Surg. 2005; Oct; 28(4): 569-75.

Franke A, Lante W, Fackeldey V, Becker HP, Kuring E, Zoller LG, Weinhold C, Maekewitz A. Is interferon gamma suppression after cardiac surgery caused by a decreased interleukin-12 synthesis? Ann Thorac Surg. 2006; Jul, 82(1):109.

Franke A, Lante W, Kuring E, Zoller LG, Weinhold C, Maekewitz A. Hyporesponsiveness of $\mathrm{T}$ cell subsets after cardiac surgery: a product of altered cell function or merely a result of absolute cell count changes in peripheral blood? Euro J Cardiothorac Surg. 2006; Jul, 30(1):64-71.

Frauwirth KA, Riley JL, Harris MH, Parry RV, Rathmell JC, Plas DR, Elstrom $\mathrm{RL}$, June $\mathrm{CH}$, Thompson $\mathrm{CB}$. The $\mathrm{CD} 28$ signaling pathway regulates glucose metabolism. Immunity 2002 Jun;16(6):769-77.

Fülöp TJR, Larbi A, Dupuis G, Pawelec G. Ageing,autoimmunity and arthristis: Perturbations of TCR signal transduction pathways with ageing $-\mathrm{a}$ biochemical paradigm for the ageing immune system. Arthritis Res Ther. Epub 2003; Oct 16. 290-302. 
Fülöp TJR, Larbi A, Douziech N, Levesqe I, Varin A, Herbein G. Cytokine receptor signalling and aging. Mechanisms of ageing and development. 2006; 127: 526-537.

Galo M, Pirttikangas C. Effects of propofol emulsion and thiopentone on $\mathrm{T}$ helper cell type-1/type2 balance in vitro. Anesthesia. 1997; 53:341.

Grahan JE, Christian LM, Kiecolt-Glaser JK. Stress, age, and immune function: toward a lifespan approach. J Behav Med. 2006; Aug;29(4):389400.

Globerson,A.; Effros,RB. Ageing of lymphocytes and lymphocytes in the aged. Immunology Today. Review October 2000; vol.21 número 10.

Goronzy JJ, Fujii H, Weyand CM. Telomeres, immune aging and autoimmunity. Exp Gerontol. 2006; Mar;41(3):246-51.

Guidi L, Tricerri A, Rasca D, Vangeli M, Errani AR, Bartoloni C. Psychoneuroimmunology and aging. Gerontoly. 1998; 44(5):247-61.

Gupta S, Su H, Bi R, Agrawal S, Gollapudi S. Life and death of lymphocytes: a role in immunesenescence. Review. Immunity and Ageing. 2005; 2:12. Han SN, Meydani SN. Vitamin E and infectious diseases in the aged. Proc Nutr Soc Aug. 1999; 58(3):697-705.

High KP. Micronutrient supplementation and immune function in elderly. Clin Infect Dis. 1999; 28(4):717-22.

Hisatomi K, Isomura T, Kawara T et al. Changes in lymphocytes subsets, mitogen responssieness and interleukin-2 production after cardiac operations. J Thora Cardiovasc Surg 1989; 98:580-591. 
Inaba K, Metlay JP, Crowley MT, Steinman RM. Dendritic cells pulsed with protein antigens in vitro can prime antigen-specific, MHC-restricted T cells in situ. J Exp Med. 1990;172:631-40.

Jansen N, Van Oeveren, $\mathrm{N}$ et al: Inhibition by dexamethasone of reperfusion phenomena in cardiopulmonary bypass. J Thorac Cardivasc Surg. 1991; 102:515-525.

Jiang J, Gross D, Elbaum P, Murasko DM. Aging affects initiation and continuation of T cell proliferation. Mech Ageing Dev. 2007; Apr;128(4);3329.

Kautor FS. Infection, anergy and cell- mediate immunity. $N$ Engl $\mathrm{J}$ Med. Review 1975; 20: 292 (12): 629- 34.

Kawasaki T, Masanori O, Kawasaki C, Tomihisa T, Okamoto K, Shigematsu A. Surgical stress induces endotoxin hyporesponsiveness and early decrease of monocyte mCD14 and HLA-DR expression during surgery. Anesth Analg. 2001; 92:1322-1326.

Kemp FW, DeCandia J, Li W, Bruening K, Baker H, Rigassio D. Relationships between immunity and dietary and serum antioxidants, trace metals, B vitamins, and homocysteine in elderly men and women. Nutr Res. $2002 ; 22: 45-53$.

Kirk CJ, Freilih AM, Miller RA. Age-related decline in activation of JNK by TCR- and CD28-mediated signals in murine T -lymphocytes. Cell Immunol. 1999; Nov 1; 197(2):75-82. 
Koch CG, Blackstone $\mathrm{EH}$ et al: Duration of red-cell storage and complications after cardiac surgery. $N$ Engl J Med. March 20, 2008; 358:1229-39.

Krause D, Mastro AM, Handte G, Smiciklas-Wright H, Miles MP, Ahluwalia N. Immune function did not decline with aging in apparently healthy, wellnourished women. Mech Ag Dev. 1999; 112(1):43-57.

Lightart B,Kim J. Simulation of airbone microbial droplet transport. Appl Environ Microbiol. 1989; Sep, 55(9):2349.

Ligthart GJ, Corberand JX, Geertzen HGM, Minders AE, Knook DL, Hijmans W. Necessity of the assessment of healthy status in human immunogerontological studies: evaluation of the SENIEUR protocol. Mech Ageing Dev. 1990; p. 89-105.

Linkskelley KW. From hormones to immunity: the physiology of immunology. Brain Behav Immun. 2004; Mar;18(2):95-113.

MacLean LD. Delayed type hypersensitivity testing in surgical patient. Surg Gynecol Obstet. Review 1988; 166(3): 285-93.

Malaguarnera $\mathrm{L}$ et al. Immunosenescence: a review. Archives in Gerontology and Geriatrics. Oxford 2001; v.32,p.1-14.

Markewitz A, Faist E, Weihold G et al: Alterations of cell-mediated immune response following cardiac surgery. Eur J Cardiothorac Surg. 1993; 7(4):193199. 
Marques CO, Laudanna E. Nutricão e nutrologia em gastroenterologia da Fugesp 2007.

McEwen BS. Physiology and neurobiology of stress and adaptation: central role of the brain. Physiol Rev. 2007; Jul,87(3):873-904.

Menon M, Jaroslow RN, Koesterer R. The decline of cell-mediated immunity in aging mice. J Gerontol. 1974; Sep,29(5): 499-505.

Mikawa K, Akamatsu H, Nishina K, Shiga M, Maekawa N, Niwa Y. Propofol inhibits human neutrophil functions. Anesth Analg.1998; 87: 695.

Miller RA, Garcia G, Kirk CJ, Witkowisk JM. Early activation defects in T lymphocytes from aged mice. Immunol Rev. 1997;150:79-90.

Miller AH, Ancoli-Israel S, Bower JE, Capuron L, Irwin MR. Neuroendocrineimmune mechanisms of behavioral comorbidities in patients with cancer. $J$ Clin Oncol. 2008; Feb, 20;26(6):971-82.

Mosmann TR, Coffman RL. Th1 and Th2 cells: different patterns of lymphokine secretion lead to different function properties. A Rev Immun. $1989 ; 7,145-173$.

Naldini A, Borrelli E, Carraro F, Giomarelli P, Toscano M. Interleukin 10 production in patients undergoing cardiopulmonary bypass: evidence of inhibition of Th-1-type responses. Cytokine. 1999; Jan,11(1):74-9. 
Novaes MRCG, Ito MK, Arruda SF, Rodrigues P,Lisboa AQ. Suplementacão de micronutrientes na senescência: implicações nos mecanismos imunológicos. Rev Nutr. 2005; vol.18 número 3.

Pawelc G. Immunity and ageing in man. Exp Gerontol. 2006; Dec,41(12):1239-42.

Pertillä J, Salo M, Pirttikangas CO, Jalonen J, Vainio O. Effects of cardiopulmonary bypass on lymphocytes and their subset counts with or without use of autotransfusion devices. J Cardiothorac Vasc Anesth. 1994; Oct;8(5):532-5.

Ramos-Casals M, García-Carrasco M, Brito MP, López-Soto A, Font J. Autoimmunity and geriatrics: clinical significance of autoimmune manifestations in the elderly. Lupus. 2003; 12(5):341-55.

Rinder CS, Mathew JP, Rinder HM, Tracey JB, Davis E, Smith BR. Lymphocyte and monocyte subset changes during cardiopulmonary bypass: effects of aging and gender. J Lab Clin Med. 1997; Jun, 129(6): 592-602.

Rizzo LV, Umetsu DT, Dekruyfl RH. Differential regulation of antigen presentation in high- and low- IgE responder mice. Eur J Immun. 1991; 21, 1767-1770.

Rizzo LV, Dekruyfl RH, Umetsu DT. Generation of B cell memory and affinity maturation. Induction with Th1 and Th2 T cell clones. J Immunol. 1992; 148:3733.

Sansoni P, Cossarizza A, Brianti V, Fagnoni F, Snelli G, Monti D, Marcato A; Passeri G, Ortolani C, Forti E, Fagiolo U, Passeri M, Franceschi C. 
Lymphocyte subsets and natural killer cell activity in healthy old-people and centenarians. Blood. 1993; 82, pp. 2767-2773.

Sansoni P, Vescovini R, Fagnoni F, Biasini C, Zanni F, Zanlari L, Telera A, Lucchini G, Passeri G, Monti D, Franceschi C, Passeri M.The immune system in extreme longevity. Exp. Gerontol. 2008; 43(2):61-5.

Shor-Posner G, Campa A, Zhang G, Prasud N, Baum MK. Obesity and immune function in the Miami HIV-1 infected drug abusers study. J Am Diet Assoc. Dec 1999; 99(12):1512.

Silva LRF. Da velhice à terceira idade: o percurso histórico das identidades atreladas ao processo de envelhecimento. História, Ciências, SaúdeManguinhos 2008; jan./mar v.15 n.1 Rio de Janeiro.

Siminelakis S, Bossinakou I. A study of the effects of extracorporeal circulation on the immunologic system of humans. J Cardioth Vasc Anesth. 1996; Dec, 10(7):893-8.

Simone R, Zicca A, Saverino D. The frequency of regulatory CD3+CD8+CD28-CD25+ $T$ lymphocytes in human peripheral blood increases with age. Journal of Leukocyte Biology. 2008; volume 84.

Solana R, Mariani E. NK and NK/T cells in human senescence. Vaccine. 2000; Feb 25;18(16):1613-20.

Steinmam RM, Hawiger D, Nussenzweig MC. Tolerogenic dendritic cells. Annu Rev Immunol. 2003;21:685-711. 
Tarazona R, Solana R, Ouyang Q, Pawelec G. Basic biology and clinical impacto f immunosenescence. Exp Gerontology. 2002 ; 183-189.

Tellado-Rodrigues I, Christou NV. Clinical assessment of host defense. Surg Clin North Am. Review 1998; 68(1) 41-55.

Udelsman R, Blake M, Stagg C, Li D, Holdbrook N. Vascular heat shock protein expression in response to stress. Endocrine and autonomic regulation of this age-dependent response. J Clin Inv. 1993; 91:465-73.

Uyemura K; Castle SC; Makinodan T. The frail elderly: role of dendritic cells in the susceptibility of infection. Mech Ageing Dev. 2002 Apr 30;123(8):95562.

Valle NS, Bárcia RN, Pawelec G, McLeod JD. Activation marker expression and apoptotic susceptibility of T-cell clonesderived from CD34(+), young and SENIEUR donors. Exp Gerontol. 2004; Apr; 39(4); 531-8.

Valen, G; Paulsson, G; Vaage, J. Induction of inflammatory mediators during reperfusion of the human heart. Ann Thorac Surg 2001 Jan; 71(1) 226-32.

Vukmanovic-Stejic M, Reed JR, Lacy E, Rustin MH, Akbar AN. Mantoux Test as a model for a secondary immune response in humans. Immunol Lett. 2006; Nov 15; 107(2):93-101.

Weksler ME, Hütteroth TH. Impaired lymphocyte function in aged humans. J Clin Invest. 1974; Jan, 53(1):99-104. 
Wu GJ, Chang H, Wang MJ,Huang FY, Peng WL. T Lymphocyte changes in open heart surgery. J Formos Med Assoc. 1991;41-45. 